\title{
LOS EXTRANJEROS RESIDENTES EN ESPAÑA: SU APORTACIÓN A LA DEMOGRAFÍA ${ }^{1}$
}

\author{
Vicente Gozálvez Pérez \\ Departamento de Geografía Humana \\ Universidad de Alicante
}

\section{RESUMEN}

La inmigración extranjera en España ha acumulado stocks muy importantes durante la última década, en su mayoría con vocación de permanencia en el país. Con ello la población de España ha crecido con las tasas más altas de su historia, apoyadas en la inmigración neta. La aportación más importante de los inmigrados a la demografía de España es su rejuvenecimiento, pues los inmigrados menores de 40 años de edad superan las tres cuartas partes de su total. Los recién llegados son adultos-jóvenes, mientras la población infantil crece mucho por su doble alimentación: reagrupación familiar y los nacidos en España de madre extranjera, lo que en parte corrige el desequilibrio producido por la persistente desnatalidad del país. Por último se analizan algunas aportaciones de los trabajadores extranjeros al mercado laboral nacional: irregularidad laboral, tasas de paro muy altas y ocupación de empleos menos valorados o rechazados por los españoles son algunas de sus características, que, en cualquier caso, dificultan la integración actual y futura de estos extranjeros en España.

Palabras clave: inmigración internacional, España, rejuvenecimiento, fecundidad, empleos de sustitución.

1 Investigación realizada dentro del Proyecto «La reagrupación familiar de los inmigrantes africanos y latinoamericanos en la España mediterránea», Ref. CSO2008-01796, financiado por el Ministerio de Ciencia y Tecnología. Investigador principal Vicente Gozálvez Pérez. Los gráficos han sido realizados por Gabino Martín-Serrano, Departamento de Geografía Humana, Universidad de Alicante. 


\section{ABSTRACT}

The number of foreign immigrants who intend to settle permanently in Spain has grown significantly over the past decade. Thus, Spain's population has increased at an unprecedented rate, which is backed up by net immigration. The most relevant contribution of foreign immigrants to Spain is the rejuvenation of demographics, as more than three quarters of immigrants are under 40 years of age. Those who have arrived most recently are young adults, whilst the child population is growing rapidly due to family reunification and foreign mothers giving birth in Spain, which in part corrects the imbalance produced by the persistent fall in the country's birth rate. Finally, the contribution of foreign workers to the Spanish job market is analysed regarding aspects such as clandestine work, extremely high rates of unemployment and the undertaking of jobs undervalued or rejected by the Spanish population, making both current and future integration of these foreigners into Spain very difficult.

Keywords: international immigration, Spain, rejuvenation, fertility rate, replacement jobs.

Las migraciones internacionales son, durante los últimos lustros, el tema de investigación geodemográfica con mayor número de publicaciones, tanto en España como en el resto de Europa occidental. Sin embargo, las temáticas tratadas se centran abrumadoramente en el extremo europeo de dichos flujos, cuando la raíz de «nuestro problema migratorio» se encuentra en los países de origen, donde estas migraciones son impulsadas, sobre todo, por su insuficiente desarrollo económico y social, por sus presiones demográficas, originadas en sus aceleradas transiciones demográficas, y por sus inestabilidades políticas, por su urbanización acelerada y por los procesos de la globalización. A los investigadores europeos siempre nos resulta más cómodo y rentable contribuir a solventar las inquietudes que origina la inmigración extranjera -sobre todo extraeuropeaen nuestro entorno social y económico, que actualmente se centran en el fuerte y acelerado crecimiento de los inmigrantes y sus abultados stocks absolutos y relativos, en los problemas que se derivan de la falta de integración de los inmigrados -adultos y escolares, futuros ciudadanos europeos-, en las especiales dificultades laborales de estos inmigrados extranjeros y sus consecuencias problemáticas, y también en las aportaciones de los inmigrantes a la geodemografía de España; todo ello a escalas variadas.

Junto a estas características del «bloque migratorio», se sitúa otra novedad demográfica que pudiera ser inquietante para el futuro: nuestra persistente desnatalidad, que ha provocado una acusada falta de efectivos en las cohortes jóvenes de la pirámide demográfica de España, y, consiguientemente, aumento 
acelerado del envejecimiento demográfico. Dado que los proyectos migratorios de los inmigrados extranjeros extraeuropeos son, según las encuestas, mayoritariamente de estabilidad y permanencia definitiva en Europa, y, en concreto, en España, la aportación de la inmigración extranjera a la demografía nacional es tema de investigación de interés creciente, igual que sucede en otros países desarrollados (Bélanger, 2009). Así, hay que resaltar que la pirámide demográfica de España siempre había hecho honor a su nombre, es decir, era una pirámide que aseguraba crecimiento demográfico por unas cohortes jóvenes siempre más numerosas que las de adultos y mayores, además, con aumento de la esperanza de vida, especialmente para los más jóvenes. En consecuencia, nuestra sociedad siempre se había planificado en el crecimiento demográfico y sus efectos positivos en la economía. Las actuales cohortes jóvenes, muy menguadas respecto a los adultos y mayores, que pueden llevar a una sociedad con menos población activa y sobre todo con menos población total si persistiera la grave desnatalidad actual, obliga a enlazar esta situación de la pirámide demográfica autóctona con los posibles aportes demográficos de los inmigrados extranjeros actuales y futuros.

La ruptura demográfica entre los actuales grupos de jóvenes y de adultos, ahora muy positiva económicamente en el supuesto de pleno empleo, podrá derivar a situación económica problemática cuando dicha ruptura ascienda y se instale entre los grupos de los adultos y de los mayores, si permaneciera la muy baja fecundidad actual, pues una inmigración extranjera sostenida y suficiente para compensar la actual desnatalidad pudiera tener costes sociales muy elevados. En cualquier caso, esta «restauración demográfica» de la pirámide de edades actual por parte de los inmigrados extranjeros también precisa, para su éxito, solventar los problemas de la integración de los inmigrantes, tanto en lo que afecta a los adultos que acaban de llegar como, sobre todo, a sus grupos infantiles, futuros ciudadanos y trabajadores en España. El grupo infantil de los inmigrantes extranjeros, sin duda, será el que crezca más por su doble «alimentación», por la inmigración de reagrupación familiar y por la natalidad de los jóvenes inmigrados que ya residen en España.

La aportación de los inmigrados extranjeros a la demografía de España se centra actualmente en el crecimiento demográfico y en el rejuvenecimiento. Pero también pueden existir contrapartidas problemáticas, como es el mayor paro laboral de los inmigrados, así como por su futura contribución al envejecimiento demográfico acelerado de España, deducido tanto del reparto actual de edades de los inmigrados como del previsible descenso de su fecundidad. 


\section{DE CRECIMIENTO CENSAL POR SALDO NATURAL A CRECIMIENTO POR INMIGRACIÓN}

España es uno de los países europeos occidentales con mayor presencia de extranjeros, 5,6 millones o el 12,1\% del total de la población empadronada a 1-01-2009. Además, estas elevadas cifras se consolidan con incrementos anuales espectaculares, especialmente durante la última década: 9,1\% en 200607 (+375.388 inmigrantes según el Padrón de habitantes), 16,6 en 2007-08 $(+749.208)$ y 7,2 en 2008-09 (+379.909). Así, la llegada de extranjeros es la responsable de que España, durante la primera década del siglo XXI, haya alcanzado el crecimiento demográfico más alto de su historia censal moderna (desde 1857), con tasas anuales de 1,67 por ciento durante 2002-06 y de 1,50 en 20062009 (Cuadro 1).

A la inmigración extranjera se debe el protagonismo, no sólo de la inflexión muy positiva en los incrementos intercensales del conjunto de España $(0,31$ por ciento anual en 1981-91, 1,60 en 2002-09), sino de la novedad de los saldos migratorios como responsables casi exclusivos de los aumentos demográficos intercensales (Cuadro 2). En efecto, hasta 1991, los saldos migratorios intercensales siempre fueron negativos, mientras los incrementos intercensales se debían exclusivamente al saldo natural; pero éste se hunde por la desnatalidad durante la década 1991-2001, cuando España sólo suma 288.396 nuevos habitantes por saldo natural. En 2002-09, el saldo natural se recupera ostensiblemente $(+620.242)$, pero ello es debido fundamentalmente a las madres extranjeras, que, en esos años, proporcionan 511.973 nacimientos. En suma, durante la última década, el aumento demográfico intercensal se reparte entre un $12,6 \%$ por saldo natural y un 87,4 por inmigración neta $(+4.287 .671)$.

Así, las dinámicas naturales y migratorias han tenido participación opuesta en los crecimientos censales antes y después de 1991: protagonismo exclusivo del saldo natural antes de ese año, mientras, en las dos últimas décadas, el saldo inmigratorio es el que domina el crecimiento demográfico de España, sobre todo durante el siglo XXI, cuando, al abultado saldo inmigratorio, se le une la participación decisiva de las madres extranjeras en el saldo natural del país.

Las cifras de inmigración indicadas, sin duda, pueden tener repercusiones positivas para la demografía de España, pero también balances preocupantes, pues cuatro quintas partes de los extranjeros han llegado desde países en desarrollo, buscando solución a sus problemas laborales, mientras España padece la tasa de paro laboral más elevada de Europa occidental. Además, son variados los indicadores de discriminación a la integración de 


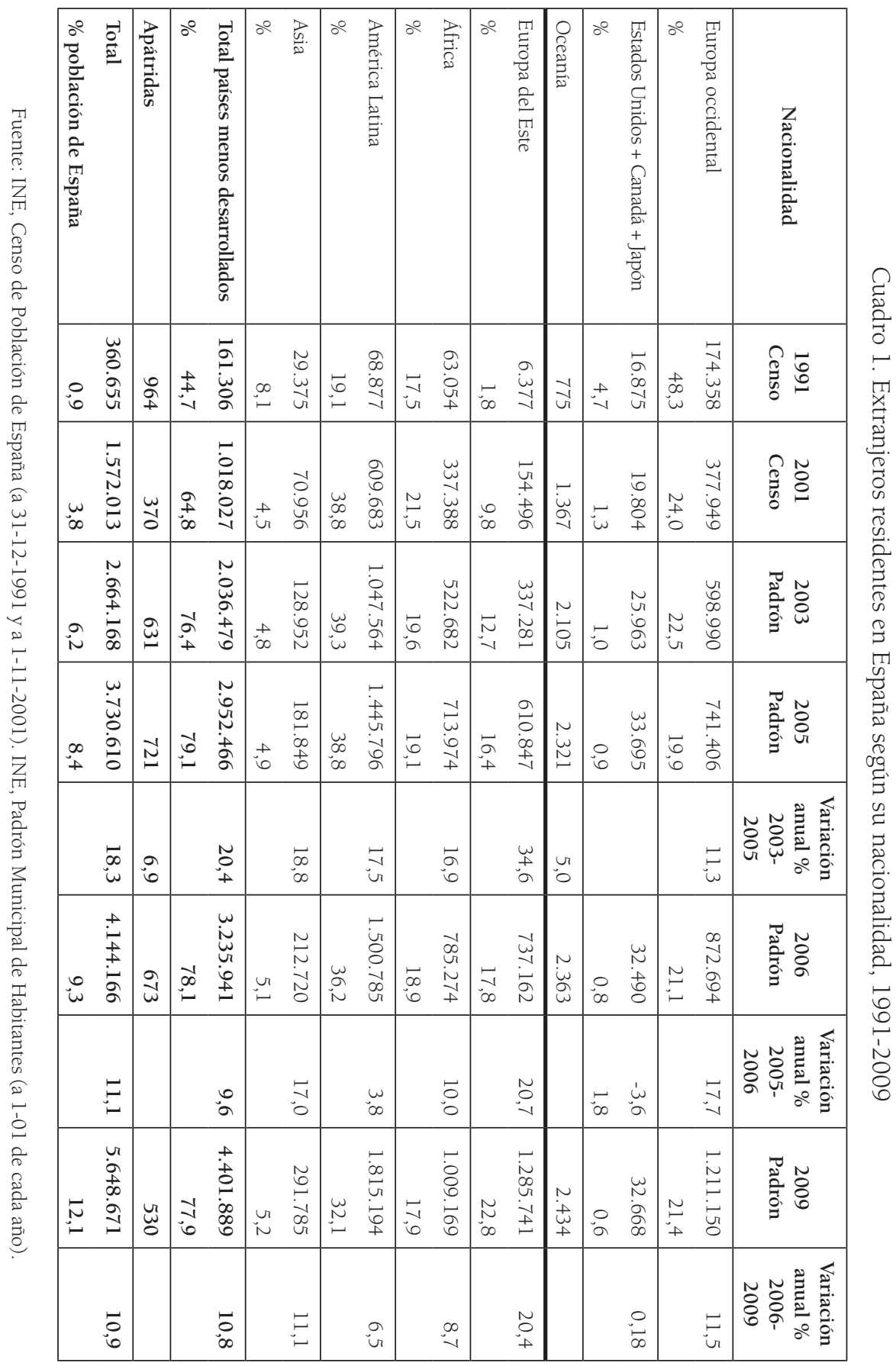


los inmigrantes -igualdad de derechos, deberes y oportunidades para nacionales y extranjeros (Dewitte, Ph., Dir., 1999)-, tal como se constata en las encuestas realizadas a los inmigrantes, y también a los españoles (Gozálvez, 2006a; Díez Nicolás, 2002). La transformación de España en «país de inmigración», en general, se ha producido al margen de un proceso equilibrado, es decir, sin oferta de empleo suficiente para los abultados contingentes de inmigrantes que han llegado, en mayoría de forma irregular y durante un periodo extremadamente corto (fig. 1). Los objetivos tanto de control de estos flujos internacionales, de acuerdo a las necesidades del mercado laboral nacional y a las posibilidades de capacidad de acogida, como de consecución de una adecuada integración de estos inmigrantes, permanecen alejados, tal como queda manifiesto en las reiteradas modificaciones de la Ley Orgánica 4/2000, de 11 de enero, sobre derechos y libertades de los extranjeros en España y su integración social, pues ya ha sido reformada en cuatro ocasiones, con sendas Leyes orgánicas de 8/2000, de 22 de diciembre, de 11/2003, de 29 de septiembre, de 14/2003, de 20 de noviembre, y de $2 / 2009$, de 11 de diciembre.

Figura 1. Evolución del número de extranjeros empadronados en España según grupos de nacionalidades

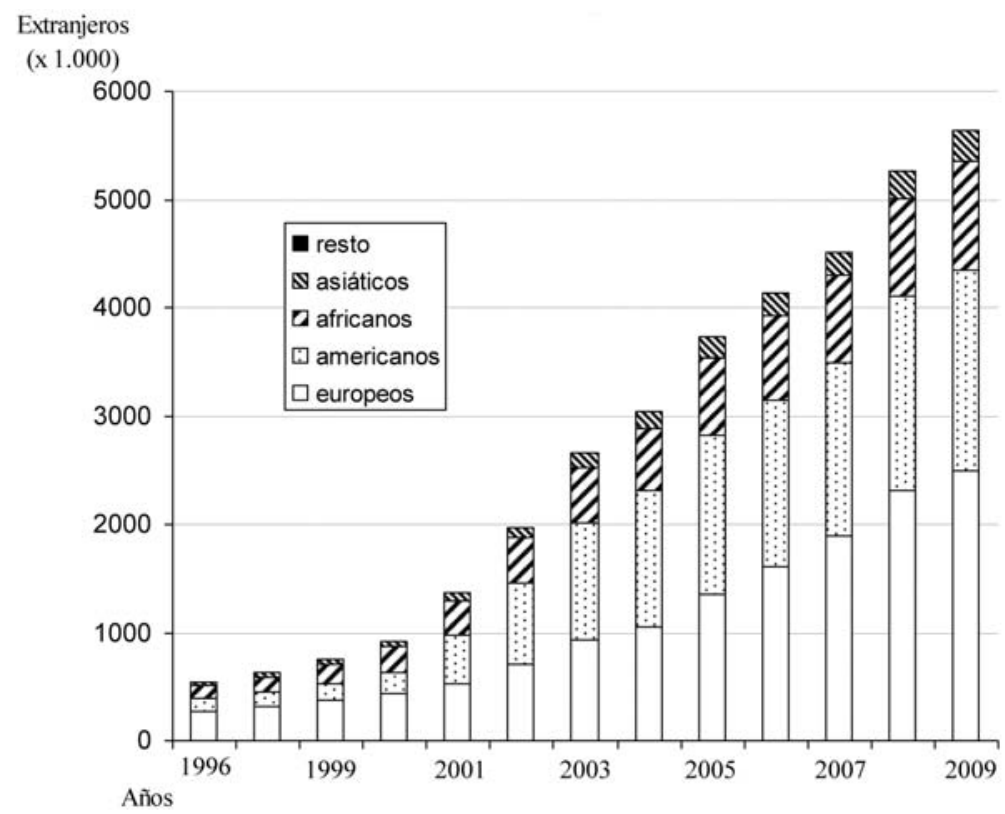

Fuente: INE, Padrón Municipal Habitantes (a 1-01 de cada año) y Censo de Población 2001 
Cuadro 2. España. Saldos naturales y migraciones netas, 1981-2009

\begin{tabular}{|c|c|c|c|c|c|}
\hline Periodo & $\begin{array}{c}\text { Población en } \\
\text { primer año }\end{array}$ & $\begin{array}{c}\text { Saldo } \\
\text { natural }\end{array}$ & $\begin{array}{c}\text { Población en } \\
\text { último año }\end{array}$ & $\begin{array}{c}\text { Saldo } \\
\text { migratorio }\end{array}$ & $\begin{array}{c}\text { Variación } \\
\text { censal } \\
\text { anual (\%) }\end{array}$ \\
\hline $1981-1991$ & 37.682 .355 & 1.189 .913 & 38.872 .268 & -94.299 & 0,31 \\
\hline $1991-2001$ & 38.872 .268 & 288.396 & 40.847 .371 & 1.686 .707 & 0,50 \\
\hline $2002-2009$ & 41.837 .894 & 620.242 & 46.745 .807 & 4.287 .671 & 1,60 \\
\hline
\end{tabular}

Fuente: INE, Censos y Padrones de población de España. Movimiento natural de la población de España

Para alcanzar los objetivos indicados -control de fronteras e integración de los inmigrados-, las políticas europeas sobre inmigración desde países menos desarrollados, deberían ser mucho más efectivas en alcanzar soluciones a las necesidades de desarrollo económico y social que padecen los países emisores de nuestros inmigrantes. Es evidente que, si no aminoran sustancialmente las brutales diferencias de desarrollo existentes -en 2008 la renta nacional en p.p.c. era, para España, de 31.130 dólares USA, frente a 5.370 para África norte, entre 1.000 y 1.600 para África subsahariana, y en torno a 8.000-10.000 para América Latina (INED, 2009)-, los flujos migratorios «forzados» y conflictivos continuarán creciendo, empujados por múltiples causas, como los efectos de la mayor información y movilidad que proporciona la globalización, la fortísima presión demográfica existente en los países menos desarrollados por efecto de su actual transición demográfica, sobre todo desde África, donde el incremento natural aún es de 2,4\% anual en 2009 (INED, 2009), o por el acelerado crecimiento de la urbanización demográfica en los países en desarrollo $-2,3 \%$ anual previsto para el periodo 2000-2030 (Véron, J., 2006)-, entre otras causas.

En conclusión, cuando se producen migraciones internacionales forzadas por las desigualdades económicas y sociales, los objetivos o soluciones que se deben alcanzar para aminorar esos flujos migratorios no se pueden centrar sólo en las medidas que convienen a uno solo de los extremos de esos flujos, los países de llegada, sino también, y con más necesidad, en el extremo inicial del flujo, los países de salida. Las causas de emigración que se padecen en los países menos desarrollados, sin duda, son más decisivas para la emigración que la atracción que ejercen los países más desarrollados. La cooperación internacional para el desarrollo de los países de origen de nuestros flujos inmigratorios -cooperación que también incluye la acción decisiva de los políticos de los países menos desarrollados-, debe alcanzar prioridades y grados de efectividad mucho mayores que los actuales, tal como denuncian las inaceptables desigualdades en renta económica, en atención sanitaria o en escolarización, entre otras (Martín Ruiz, 2007). 


\section{LA DIVERSIDAD DE LOS EXTRANJEROS EN ESPAÑA}

Los extranjeros que residen en España ofrecen diversidades muy destacadas que, a su vez, pueden influir decisivamente en aspectos trascendentales como es su integración en la sociedad española. Este es el caso de la multiplicidad de procedencias geográficas de estos extranjeros. Así, los europeos y latinoamericanos, que suman 4,3 millones (Cuadro 1)(Fig. 1), comparten muchos aspectos culturales con los españoles, por lo que son, según todas las encuestas, los extranjeros mejor aceptados. Por el contrario, la distribución territorial contrastada de los extranjeros en España, visible en cualquier escala (entre provincias, municipios, barrios de una ciudad, e incluso entre edificios), ofrece excesivas concentraciones, lo que sin duda puede tener efectos negativos para la integración, sobre todo si los contrastes territoriales se refuerzan con contrastes culturales entre las comunidades de extranjeros.

\subsection{España, encrucijada para la inmigración internacional}

La distribución y volúmenes de los extranjeros según su origen geográfico muestran cómo España ya es una encrucijada para la inmigración internacional (Cuadro 1 y 3). En esta diversidad de orígenes intervienen distintas causas, como la influencia colonial española, que creó una gran área con sólidos vínculos históricos-culturales -Latinoamérica-, la vecindad -para Marruecos-, así como las nuevas lógicas migratorias de la globalización, por las que la atracción se extiende, por motivos económicos, hasta países muy lejanos y sin ningún tipo de vínculo histórico con España, como China o Europa del Este; en este último caso, la reciente ampliación de la Unión Europea a una parte de estos países ha sido determinante para su inmigración (Rumanía, Bulgaria). La atracción para los europeos occidentales se apoya en motivos culturales y de proximidad, que, a su vez, facilitan los motivos residenciales sobre los litorales marítimos de España, aunque cada vez influyen más los motivos económicos, determinantes para las colonias de italianos y portugueses, con incrementos muy importantes durante los últimos años (cuadro 3). A escalas de detalle, son las redes migratorias establecidas entre inmigrados y sus familiares y amigos residentes en el país de origen las que configuran los diversos flujos desde el interior de cada país, tal como manifiestan expresamente los inmigrados encuestados durante la última década (Gozálvez y Equipo, 1995, 2006, 2008).

Todos los grandes grupos de origen de los extranjeros residentes en España alcanzan colonias muy cuantiosas (cuadro 1): los africanos son más de 1 millón, los latinoamericanos, 1,8 millones, mientras los europeos suman 2,5 millones, distribuidos por mitad entre Europa occidental y Europa del este. Así, tienen culturas más o menos afines a la de los españoles el 76\% de los extranjeros, y de éstos, el 30\% hablan español como lengua materna. Los africanos y asiáticos, 
más alejados de la cultura autóctona, sólo representan el 23 por ciento de todos los extranjeros.

Cuadro 3. Países con más de 100.000 extranjeros residentes en España en 2009

\begin{tabular}{|c|c|c|c|}
\hline & \multicolumn{2}{|c|}{ Inmigrantes } & \multirow{2}{*}{$\begin{array}{l}\text { Variación anual } \\
2006-2009, \%\end{array}$} \\
\hline & 2009 & 2006 & \\
\hline Rumanía & 798.892 & 407.159 & 25,2 \\
\hline Marruecos & 718.055 & 563.012 & 8,4 \\
\hline Ecuador & 421.426 & 461.310 & $-3,0$ \\
\hline Reino Unido & 375.703 & 274.722 & 11,0 \\
\hline Colombia & 296.674 & 265.141 & 3,8 \\
\hline Bolivia & 230.703 & 139.802 & 18,2 \\
\hline Alemania & 191.002 & 150.490 & 8,3 \\
\hline Italia & 175.316 & 115.791 & 14,8 \\
\hline Bulgaria & 164.717 & 101.617 & 17,5 \\
\hline China & 147.479 & 104.681 & 12,1 \\
\hline Argentina & 142.270 & 150.252 & $-1,8$ \\
\hline Portugal & 140.870 & 80.635 & 20,4 \\
\hline Perú & 139.179 & 95.903 & 13,2 \\
\hline Brasil & 126.185 & 72.441 & 20,3 \\
\hline Francia & 120.507 & 90.021 & 10,2 \\
\hline Total parcial & 4.188 .978 & 3.072 .977 & 10,9 \\
\hline$\%$ & 74,2 & 74,2 & \\
\hline Totales & 5.648 .978 & 4.144 .166 & 10,9 \\
\hline
\end{tabular}

Fuente: INE, Padrón Municipal de Habitantes, a 1-01 de cada año

Todos los continentes tienen algún país con más de 100.000 residentes en España (Cuadro 3): de los 15 países que superan este umbral en 2009, 7 son europeos, todos de la UE, aunque lleguen por motivos tan dispares como los británicos (376.000) o los rumanos (800.000), cuya reciente incorporación a la UE ha facilitado que este colectivo crezca un 25 por ciento anual entre 2006 y 2009, y se haya doblado el censo de rumanos empadronados en España. De los 6 países latinoamericanos que superan los 100.000 inmigrados en España, tanto Ecuador -el mayor censo de los de esta procedencia- como Argentina, con los inmigrados mejor integrados en España, han disminuido sus colonias entre 2006 y 2009; por el contrario, Bolivia, con la renta más baja de América del sur, ha aumentado sus inmigrantes en España un 18,2 por ciento anual durante estos tres años. El 60 por ciento de los inmigrantes latinoamericanos proceden de los cuatro países andinos con menor renta (Cua- 
dro 3), entre 4.100 y 8.500 dólares USA en p.p.c. en 2008 (INED, 2009). Aunque los inmigrantes latinoamericanos establecen su residencia en las grandes ciudades españolas para trabajar en el sector terciario, en los últimos años, buena parte de los inmigrantes andinos también se ha concentrado en las provincias que ofrecen trabajo en la agricultura hortícola intensiva, fundamentalmente en Murcia (86.600 latinoamericanos en 2009, de los que 47.000 son ecuatorianos y 19.000 bolivianos).

Respecto a estos distintos comportamientos recientes de los flujos migratorios de los latinoamericanos, 330 mujeres latinoamericanas encuestadas en 2003-2005, residentes en las ocho provincias entre Girona y Almería, manifestaron un deseo de permanencia en España -para ellas y para sus hijos- netamente inferior al de las mujeres africanas. Así, a la pregunta "¿cuánto tiempo piensa permanecer en España?», respondieron «para siempre» el 44\% de las magrebíes, frente a un 25\% de las latinoamericanas; por el contrario, la inmigración de corta duración -hasta un máximo de 3 años- tiene un rechazo casi total en las africanas, pero sí la desea el 12\% de las latinoamericanas, lo que estaría en consonancia con la reciente disminución del stock de inmigrantes ecuatorianos y argentinos. Igualmente, la permanencia en España a medio o largo plazo de los hijos de las inmigradas encuestadas es deseada por el $47 \%$ de las magrebíes frente al 38 por ciento de las latinoamericanas (Gozálvez y Equipo, 2008b: 169).

Los 718.000 marroquíes empadronados en España en 2009 son el segundo colectivo nacional extranjero, pero, sin duda, son los inmigrados con mayor estabilidad actual y futura, pese a que se les atribuye notables dificultades para su integración en la sociedad española, tanto por la negativa valoración de los españoles sobre estos inmigrantes como por la autocalificación de los propios marroquíes (Gozálvez y Equipo, 2006a; Díez Nicolás, 2002). Como se ha indicado, las mujeres magrebíes encuestadas se muestran como las más proclives a su permanencia definitiva en España; además, también son indicadores de estabilidad residencial su aporte a la natalidad en España, el mayor entre las madres extranjeras (25.400 nacimientos de madre marroquí en 2009), aunque su tasa de feminización aún es de las más bajas (38 por ciento del total de esta colonia en España). La misma conclusión se deduce de sus autorizaciones de residencia permanente, pues a 31-08-2008 esta situación afectaba a más de la mitad de los marroquíes frente a la cuarta parte entre los ecuatorianos, o el 20\% de los colombianos (Ministerio de Trabajo, 2008).

Finalmente, los 147.500 chinos empadronados en España representan más de la mitad de todos los asiáticos. Su empleo casi siempre se realiza al margen de la población autóctona, tradicionalmente en actividades de restauración y de comercio, y, más recientemente, también en el comercio de distribución de productos importados desde su país. El crecimiento de la presencia femenina -aún escasa- entre los asiáticos, el decidido aumento de nacimientos de madre asiáti- 
ca, así como el aumento de los menores de 15 años de edad, son indicadores de crecimiento y estabilidad de esta colonia.

\subsection{Una distribución territorial muy contrastada}

Los contrastes territoriales de los extranjeros en España son visibles en todas las escalas (Cutillas, 2006; Bayona, 2007); ahora nos referimos a las provincias. La media de extranjeros para el conjunto de España es de 12,1\% del total de la población empadronada a 1-01-2009. En la distribución provincial de los extranjeros, Alicante alcanza la proporción máxima, 24,2\%, mientras en Jaén sólo son el 2,4 por ciento. Además, la concentración de Alicante se acentúa mucho en su litoral y prelitoral marítimo: en 2008 ya son 19 los municipios de esta provincia con mayoría de población extranjera, incluso en municipios que superan los 100.000 habitantes, como Torrevieja. Como muestra el mapa (fig. 2), los mayores contingentes y la mayoría de las provincias con proporciones de extranjeros superiores al 16 por ciento de su población total se localizan en la fachada mediterránea, pues aquí se superponen motivos de atracción que interesan a los extranjeros de todas las procedencias.

Figura 2. Proporción de extranjeros sobre la población total de las provincias, 2009

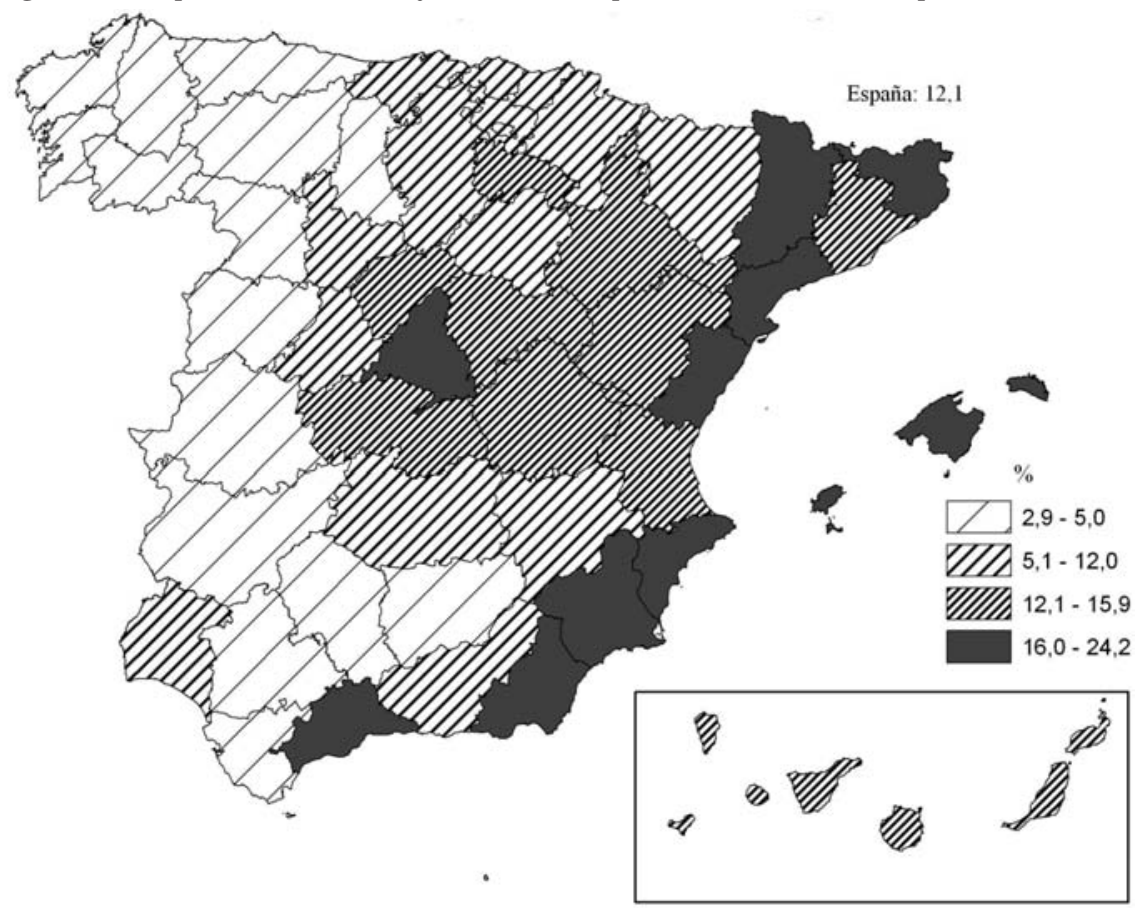

Fuente: INE. Padrón municipal de habitantes a 01-01-2009

Investigaciones geográficas, nº 52, pp. 99 - 135 
En efecto, para los europeos occidentales empadronados en este litoral resulta fundamental la benignidad residencial que proporcionan el clima, el paisaje y la accesibilidad. Alicante tiene la mayor concentración (245.000) de los de esta procedencia -más de la mitad son británicos-, seguida de Málaga (138.000) y Baleares (97.000), es decir, los litorales más especializados en la función turística residencial, aunque, entre estos extranjeros, además de jubilados, sobresalen activos vinculados a la función turística y residencial de sus connacionales. Otras características de la fachada mediterránea atractivas para el asentamiento de extranjeros es su urbanización, tanto en ciudades grandes -Barcelona, Valencia-, como medias o pequeñas, así como en urbanización difusa. En toda esta área litoral se origina economía variada y, con frecuencia, «propensa» al trabajo irregular o no controlado -sobre todo en los sectores de servicios, agricultura y construcción-, tan «necesario» para los que llegan a España por motivos de necesidad económica y de modo irregular. En la fachada mediterránea se produce una generalizada agricultura minifundista, tanto frutícola como hortícola, cuya mayoría de trabajadores asalariados son inmigrantes africanos y latinoamericanos andinos (Gozálvez; López Trigal, 1999).

Los extranjeros también alcanzan presencias muy relevantes en los archipiélagos (Zapata, 2002), donde se produce destacada función turística y alta proporción de europeos occidentales, así como en Madrid, debido a las funciones económicas propias de su gran tamaño demográfico y de capital del Estado, lo que atrae elevados contingentes de extranjeros de todas las procedencias (Méndez, 2008). Madrid es primer destino provincial para los procedentes de Europa del Este (293.000 en 2009) y, sobre todo, para los latinoamericanos que suman 480.700 de sus 1,1 millones de residentes extranjeros. Barcelona, en cambio, es el primer destino para los africanos (178.000) y para los asiáticos (97.000), mientras que Alicante concentra la colonia más numerosa de europeos occidentales (245.000). En cualquier caso, todos los grandes colectivos continentales de extranjeros, en general, localizan la mayor parte de sus contingentes según la tendencia general que ofrece el mapa (fig. 2), es decir, la inmigración más reciente acude a las zonas donde el dinamismo económico es mayor, acentuando así los desequilibrios demográficos crecientes del país, pues el dinamismo económico se acompaña de mayores densidades y juventud demográficas.

No obstante, los mapas con la distribución provincial de los grandes colectivos de extranjeros también difieren entre sí (Gozálvez y Equipo, 2008a) debido a sus diferentes habilidades laborales y lingüísticas, a las posibilidades laborales locales que cada colectivo pueda aprovechar mejor, e incluso según predominen para cada procedencia unas u otras fronteras de acceso a España, es decir, las aéreas para los latinoamericanos, las marítimas desde África o las continentales para los europeos del Este. 


\section{LA ESTRUCTURA POR EDAD Y SEXO DE LOS EXTRANJEROS: APOYO AL REJUVENECIMIENTO DEMOGRÁFICO DE ESPAÑA}

La estructura por edad de los extranjeros que residen en España se reparte entre dos grupos muy desiguales. El grupo menos numeroso -1,3 millones de extranjeros en 2009 (Cuadro 1) - lo forman los que proceden de países más desarrollados, que tienen envejecimiento acusado, incluso superior al de la población española; por el contrario, el grupo más numeroso, con 4,4 millones de extranjeros, tiene una estructura muy joven; este grupo es heterogéneo por su origen geográfico -todos los continentes están bien representados- pero muy homogéneo tanto por los motivos económicos-laborales de su inmigración como por su acentuada juventud (Cuadro 4) y el carácter muy reciente de su llegada a España (Cuadro 1).

Como muestra la fig. 3, los extranjeros se acumulan de forma muy destacada en las cohortes de los adultos jóvenes -20 a 39 años de edad-, donde suman 2,8 millones; por el contrario, entre los que superan los 65 años de edad, los extranjeros sólo suman 622.000 empadronados. Como indicador de actualidad -escolarización- y de futuro -futuros trabajadores y procreadores-, interesa destacar que los extranjeros que tienen menos de 15 años de edad, que en 2009 son 807.000, es el grupo que tenderá a ganar más peso tanto por la creciente reagrupación familiar en España de los extranjeros (Domingo y otros, 2010) como por su natalidad (en 2008 proporcionan el 21\% de todos los nacimientos registrados en España). Así pues, pese al envejecimiento de los extranjeros originarios de países desarrollados, el balance global de la población extranjera favorece de forma destacada el rejuvenecimiento de la población total empadronada en España.

Figura 3. Población de España por edad y sexo, a 01-01-2009. Cifras absolutas

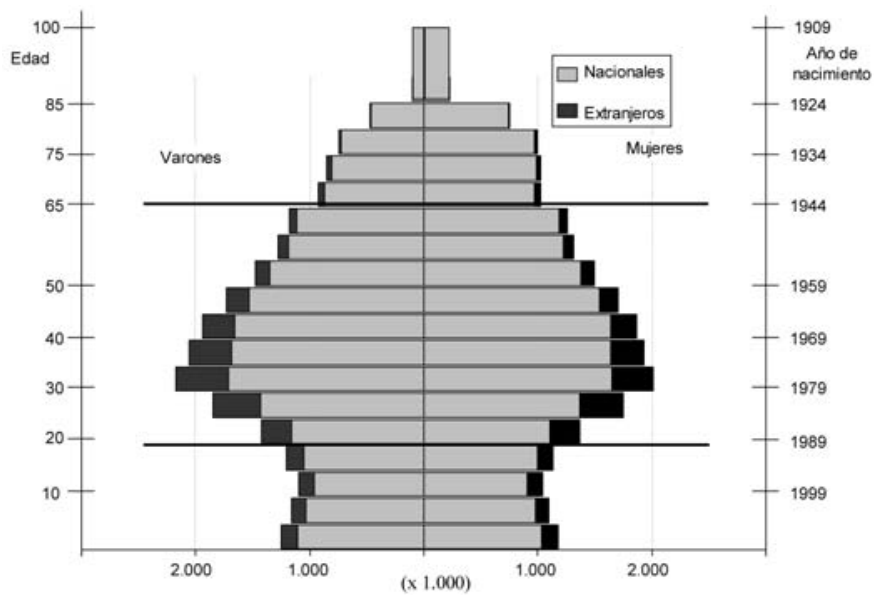

Fuente: INE, Padrón Municipal de habitantes, 01-01-2009 


\begin{tabular}{|c|c|c|c|c|c|c|c|c|c|c|c|c|c|c|c|c|c|c|}
\hline$\tilde{s}$ & $\circ$ & $\begin{array}{l}\frac{g}{\sigma} \\
\frac{\sigma}{4}\end{array}$ & \begin{tabular}{l}
$\mathfrak{\gamma}$ \\
\multirow{+}{*}{}
\end{tabular} & & $\begin{array}{c}0 \\
\tilde{n} \\
m\end{array}$ & $\vec{n}$ & & $\begin{array}{l}\sim \\
\stackrel{+}{n} \\
i n\end{array}$ & $\begin{array}{l}n \\
\stackrel{n}{*} \\
\stackrel{1}{n}\end{array}$ & & $\begin{array}{l}n \\
\hat{b}^{-} \\
n^{2}\end{array}$ & $\overrightarrow{\infty^{0}}$ & & \begin{tabular}{l}
0 \\
\multirow{5}{f}{}
\end{tabular} & $\begin{array}{l}i^{2} \\
\stackrel{n}{f}\end{array}$ & & $\begin{array}{l}0 \\
0 \\
i\end{array}$ & $\begin{array}{l}\text { in } \\
\text { in }\end{array}$ \\
\hline$\stackrel{\vec{\Xi}}{\Sigma}$ & 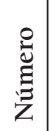 & 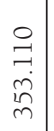 & $\begin{array}{l}\frac{u}{q} \\
b \\
n \\
0 \\
\sigma\end{array}$ & $\stackrel{+}{\stackrel{i}{d}}$ & 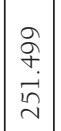 & $\begin{array}{l}\hat{\hbar} \\
\hat{\vdots} \\
\hat{n} \\
\tilde{m}\end{array}$ & $\overrightarrow{\mathfrak{z}}$ & $\begin{array}{l}\stackrel{0}{1} \\
0 \\
\dot{+} \\
\infty\end{array}$ & \begin{tabular}{|l|}
$\infty$ \\
0 \\
0 \\
$\dot{0}$ \\
$\dot{2}$ \\
$\alpha$
\end{tabular} & $\hat{0}$ & $\begin{array}{l}\stackrel{1}{N} \\
\stackrel{N}{N}\end{array}$ & $\begin{array}{l}\stackrel{n}{0} \\
\stackrel{-}{\exists} \\
\exists\end{array}$ & $\hat{\beth}$ & $\begin{array}{l}\stackrel{2}{ } \\
\underset{\sim}{\sim} \\
\tilde{\sigma}\end{array}$ & 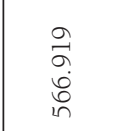 & $\begin{array}{l}n \\
a\end{array}$ & & \\
\hline $\begin{array}{l}\text { ¿ } \\
\text { : } \\
\text { : }\end{array}$ & $\circ^{\circ}$ & $\begin{array}{l}0 \\
0 \\
0\end{array}$ & $\begin{array}{l}\infty \\
0 \\
0\end{array}$ & & $\stackrel{\sim}{\sim}$ & $\stackrel{0}{-1}$ & & $\stackrel{\vartheta}{\approx}$ & $\approx$ & & $\stackrel{\infty}{\leftarrow}$ & $\cong$ & & $\begin{array}{l}+ \\
\stackrel{+}{-}\end{array}$ & $\begin{array}{c}m \\
\infty^{\prime}\end{array}$ & & $\hat{\sigma}^{\circ}$ & $\begin{array}{l}0 \\
0 \\
0 \\
-1\end{array}$ \\
\hline 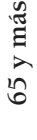 & 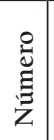 & $\begin{array}{l}\stackrel{\bullet}{0} \\
\stackrel{+}{*}\end{array}$ & $\begin{array}{l} \pm \\
\vdots \\
\vdots \\
\sigma\end{array}$ & مै & 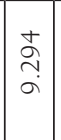 & 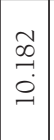 & $\vec{m}$ & $\begin{array}{l}\infty \\
\stackrel{n}{n} \\
\stackrel{\sim}{\sim}\end{array}$ & \begin{tabular}{|l|}
$\infty$ \\
0 \\
0 \\
0 \\
$\dot{m}$ \\
\end{tabular} & $\stackrel{0}{m_{0}^{\prime}}$ & $\begin{array}{l}\vec{b} \\
n \\
m\end{array}$ & \begin{tabular}{|l}
$\vec{b}$ \\
$\stackrel{+}{+}$ \\
$\dot{f}$
\end{tabular} & $\stackrel{\sim}{f}$ & $\begin{array}{l}\hat{n} \\
\hat{\alpha} \\
\hat{n} \\
n\end{array}$ & \begin{tabular}{l}
$\infty$ \\
$\infty$ \\
$\infty$ \\
$\stackrel{\sim}{\sim}$ \\
\multirow{N}{*}{}
\end{tabular} & $\stackrel{0}{\stackrel{m}{r}}$ & & \\
\hline$\stackrel{\mathscr{c}}{g}$ & $\circ$ & $\vec{\sim}$ & $\begin{array}{l}\tilde{n} \\
\tilde{\sim}\end{array}$ & & $\begin{array}{l}\exists \\
=\end{array}$ & $\begin{array}{l}a \\
-1 \\
-1\end{array}$ & & $\stackrel{n}{\vec{\sim}}$ & $\begin{array}{l}\hat{z} \\
\hat{z}\end{array}$ & & 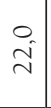 & $\begin{array}{l}\infty \\
\tilde{N}\end{array}$ & & $\begin{array}{l}0 \\
\dot{q} \\
\dot{q}\end{array}$ & $\begin{array}{l}+\dot{ } \\
\mathfrak{m}^{\prime}\end{array}$ & & $\stackrel{+}{m}$ & $\begin{array}{l}0 \\
\tilde{i}\end{array}$ \\
\hline $\begin{array}{l}0 \\
\vdots \\
0 \\
+\end{array}$ & 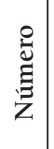 & $\begin{array}{l}0 \\
\vdots \\
n \\
n \\
n \\
n\end{array}$ & $\begin{array}{l}\vec{n} \\
\hat{b} \\
\grave{i} \\
\tilde{m}\end{array}$ & $\begin{array}{l}\infty \\
\stackrel{\sim}{\sim}\end{array}$ & $\begin{array}{l}0 \\
0 \\
0 \\
+ \\
\dot{\sim} \\
-\end{array} \mid$ & 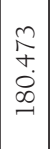 & $\hat{\sigma}$ & 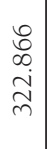 & 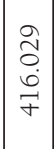 & $\begin{array}{l}\infty \\
\infty \\
\infty\end{array}$ & $\begin{array}{l}8 \\
\stackrel{1}{0} \\
6 \\
+\end{array}$ & 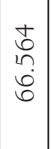 & $\stackrel{n}{\approx}$ & $\begin{array}{l}n \\
\infty \\
\infty \\
\infty \\
0 \\
m\end{array}$ & \begin{tabular}{l}
$m$ \\
\multirow{2}{*}{} \\
$\infty$ \\
$\stackrel{0}{+}$ \\
+
\end{tabular} & $\vec{a}$ & & \\
\hline$\approx$ & $\circ$ & $\begin{array}{l}\dot{v} \\
\hat{b}\end{array}$ & $\hat{\vec{b}}$ & & 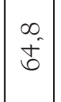 & $\begin{array}{c}0 \\
i \\
\end{array}$ & & $\mid \begin{array}{l}\vec{*} \\
\vec{\sigma}\end{array}$ & $\stackrel{n}{-}$ & & $\begin{array}{l}\tilde{\tilde{G}} \\
\mathrm{G}\end{array}$ & $\begin{array}{c}0 \\
8 \\
8\end{array}$ & & $\vec{m}$ & $\stackrel{0}{m}$ & & $\mid \begin{array}{l}0 \\
n \\
m\end{array}$ & 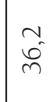 \\
\hline ले & 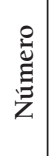 & $\begin{array}{l}m \\
\vec{F} \\
\underset{j}{+} \\
\stackrel{+}{\sigma}\end{array}$ & 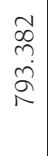 & $\begin{array}{c}0 \\
\infty \\
\infty^{0}\end{array}$ & 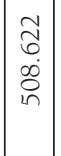 & $\mid \begin{array}{l}0 \\
0 \\
0 \\
0 \\
0 \\
0\end{array}$ & $\hat{a}$ & $\mid \begin{array}{c}\infty \\
\infty \\
o \\
\vec{\sim} \\
\sigma\end{array}$ & 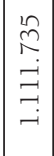 & $\stackrel{+}{\sigma}$ & $\begin{array}{l}\vec{J} \\
\vec{\forall} \\
\underset{\sim}{二}\end{array}$ & 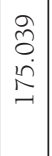 & $\hat{a}$ & 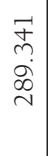 & $\begin{array}{l}\hat{\delta} \\
\text { m. } \\
\infty \\
F\end{array}$ & $\vec{m}$ & & \\
\hline 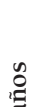 & $\circ$ & $\begin{array}{l}\infty \\
\underset{\exists}{-1}\end{array}$ & $\begin{array}{l}0 \\
\pm \\
\pm\end{array}$ & & $\begin{array}{c}0 \\
-1 \\
-1\end{array} \mid$ & $\overrightarrow{0}$ & & $\begin{array}{l}n \\
2 \\
n\end{array}$ & $\overrightarrow{ \pm}$ & & $\begin{array}{l}0 \\
\pm \\
\pm\end{array}$ & $\begin{array}{l}n \\
i n\end{array}$ & & $\overrightarrow{0}$ & $\hat{a}$ & & $\begin{array}{l}m \\
\stackrel{m}{ \pm}\end{array}$ & $\begin{array}{l}0 \\
\pm \\
\pm\end{array}$ \\
\hline $\begin{array}{l} \pm \\
1 \\
0\end{array}$ & 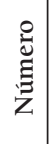 & $\begin{array}{l}\hat{n} \\
n \\
\vdots \\
\vdots\end{array}$ & $\begin{array}{l}8 \\
+ \\
+ \\
\infty \\
\infty\end{array}$ & $\begin{array}{l}\stackrel{0}{\text { d }} \\
\dot{\sim}\end{array}$ & $\left|\begin{array}{l}N \\
N \\
N \\
\tilde{n}\end{array}\right|$ & 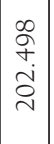 & in & 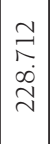 & $\mid \begin{array}{l}\tilde{N} \\
0 \\
0 \\
\sim \\
\sim \\
\sim\end{array}$ & $\hat{m}$ & $\begin{array}{l}n \\
\hat{n} \\
\stackrel{2}{2} \\
\grave{2}\end{array}$ & $\mid \begin{array}{l}\vec{a} \\
\grave{f} \\
\dot{f}\end{array}$ & $\begin{array}{l}0 \\
10 \\
n\end{array}$ & $\begin{array}{l}\infty \\
\stackrel{n}{n} \\
\sim \\
\vdots\end{array}$ & $\begin{array}{l}\stackrel{\theta}{\exists} \\
\exists \\
\vec{I}\end{array}$ & $\hat{\sigma}$ & & \\
\hline 安 & & $\begin{array}{l}\stackrel{8}{ } \\
\stackrel{\sim}{0} \\
\end{array}$ & 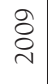 & & 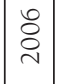 & 客 & & 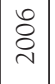 & 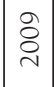 & & \begin{tabular}{l}
0 \\
$\vdots$ \\
\hdashline \\
\end{tabular} & 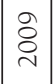 & & 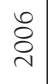 & ஓి & & \begin{tabular}{l}
0 \\
\multirow{2}{0}{} \\
\multirow{2}{*}{}
\end{tabular} & 高 \\
\hline . & שֶ, & 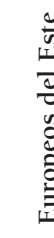 & 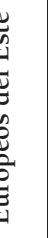 & 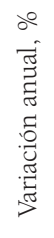 & $\begin{array}{l}\text { v } \\
0 \\
0 \\
0\end{array}$ & E. & 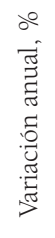 & $\begin{array}{l}y \\
0 \\
0 \\
0\end{array}$ & 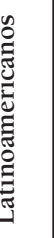 & 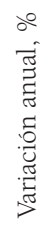 & $\frac{5}{4}$ & 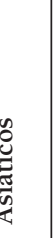 & 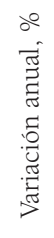 & & 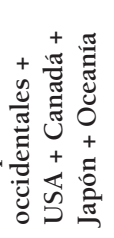 & 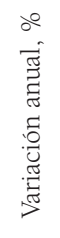 & & 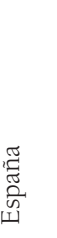 \\
\hline
\end{tabular}


Los extranjeros menores de 40 años de edad alcanzan proporciones bastante distantes del conjunto de la población empadronada en España. Así, la media nacional indica que el 51\% de la población tiene menos de 40 años de edad, pero, entre los extranjeros de países desarrollados, esta proporción se reduce al 43 por ciento, mientras que para los que proceden de países en desarrollo, sube el 77 por ciento. Por el contrario, entre los que superan los 40 años de edad la situación es inversa: la media nacional incluye en estas edades al 49\% del censo, pero esta proporción sube hasta el 57 por ciento entre los extranjeros de países desarrollados, y se reduce al 23 por ciento entre los que proceden de países en desarrollo.

Entre los ciudadanos que proceden de los países más desarrollados de Europa occidental, la proporción de los que tiene 65 y más años de edad puede doblar la cifra media del total de este colectivo (18,3\%), sobre todo los de Suiza, que tienen un 37\% de jubilados, Noruega, 33\%, Dinamarca, Alemania y Suecia, 27\%, Reino Unido, 24\% ...; además, en los últimos años se acentúa el envejecimiento de los residentes que proceden de los países europeos atlánticos. Sin embargo, los jubilados que proceden de los países europeos mediterráneos occidentales tienen proporciones bajas, pues estos extranjeros tienen un marcado carácter laboral, como ocurre con los italianos (6,6\% mayores de 65 años en 2009), portugueses $(4,2)$ o franceses $(12,2)$. Por el contrario, el grupo con 65 y más años sólo representa el 1,2 por ciento de los 4,4 millones de extranjeros que proceden de países menos desarrollados, pues esta inmigración ha llegado muy recientemente (Cuadro 1, fig. 1) y por motivos económico-laborales. La distribución etaria incluso muestra la influencia de la secuencia temporal de llegadas, pues los inmigrantes más recientes, los europeos del Este, todavía no alcanzan el 1 por ciento en su grupo de mayores, mientras los africanos «llenan» con cierta celeridad la base de su pirámide demográfica (20,1\% tienen menos de 15 años de edad), en lo que sin duda influye su estabilidad residencial en España, su progresiva feminización, aunque aún escasa, su mayor fecundidad, como se explicará, y su reciente reagrupación familiar.

Los extranjeros menores de 15 años de edad aumentan con celeridad en cifras absolutas y relativas. La única excepción es la de los que proceden de los países más desarrollados, lo que es acorde al fuerte envejecimiento entre estos extranjeros residentes en España; en cualquier caso, los niños de este último grupo ya suman más de 121.000 en 2009, mientras que los hijos de extranjeros procedentes de países menos desarrollados son 686.000. Si comparamos la proporción de estos niños con el total de cada colectivo geográfico, llama mucho la atención que, entre los que proceden de países menos desarrollados, pese a lo reciente de esta inmigración, las proporciones de niños son iguales o superiores a las del conjunto de los empadronados en España, pues si éstos tienen una proporción de niños del 14,6\% en 2009, los africanos alcanzan el 20,1 y los asiáticos el 15,7. Para el periodo 2006-09, la variación anual 
positiva de los grupos infantiles es superior a la del conjunto de sus colectivos, con la excepción de los niños latinoamericanos; para los europeos del Este, la variación anual infantil alcanza el 24\%, y el 15\% entre los asiáticos y africanos; es decir, alcanzan tasas de crecimiento extraordinario precisamente los niños que más problemas escolares pueden tener si atendemos a las lenguas de sus países de origen. En su conjunto, los niños extranjeros en edad escolar obligatoria (menores de 15 años) se han multiplicado por 3,5 entre 2001 (231.560 censados) y 2009 (806.757), de los cuales 550.000 tienen nacionalidad de países con lengua distinta al español.

Los cuatro grupos geográficos de inmigrados laborales (europeos del Este, africanos, latinoamericanos y asiáticos) tienen una estructura por edad muy similar (cuadro 4), caracterizada por su juventud, pues, entre el 60 y 65 por ciento, tienen edades comprendidas entre 15 y 39 años, lo que se refleja en su natalidad. Por el contrario, la proporción de adultos-jóvenes se reduce a la mitad entre los extranjeros procedentes de países desarrollados.

La pirámide de edades nos muestra cómo los inmigrados extranjeros refuerzan mucho las cifras de población total de España entre 25 y 40 años de edad (fig. 3), cuyas cohortes se sitúan, así, en condiciones ideales de partida para aumentar la productividad económica y demográfica de España, aunque las crisis actuales en uno y otro aspecto malogran estas excelentes posibilidades. Por el contrario, si consideramos esta distribución etaria con una perspectiva de veinte años, la actual población extranjera acumulada sobre las mismas cohortes del baby boom (nacidos entre 1960 y 1976) podrá acelerar en su día el envejecimiento demográfico.

La feminización o proporción de mujeres en los distintos colectivos de extranjeros tiene notables matices según los grupos geográficos, aunque todos evolucionan buscando el equilibrio entre varones y mujeres. Así, mientras para el conjunto de los españoles las mujeres representan el 51\% del total, los inmigrados latinoamericanos son el único grupo en que las mujeres alcanzan mayoría, pues sobrepasan el 54 por ciento de su total. Sin embargo, en los abultados contingentes llegados desde Latinoamérica durante los últimos años, los varones han ganado mucho peso, pues en 1998 las mujeres de esta procedencia alcanzaban dos tercios del total. No obstante, hay diferencias muy notables entre las diversas nacionalidades: así, las feminizaciones más altas son las de Paraguay, con 65\%, Brasil, América Central y Bolivia (56\%); por el contrario, las mujeres tienen paridad con los varones entre los inmigrados de Argentina, Perú o Ecuador. En el resto de grupos geográficos de inmigrantes, las mujeres son minoría, pero con claras diferencias: entre los europeos se acercan a la paridad con los varones, mientras entre los asiáticos y africanos la proporción de mujeres sólo alcanza en 2009 el 38\% y 35\%, respectivamente, aunque con rápido proceso de aumento de la feminización, en lo que, sin duda, influye decisivamente la reciente reagrupación familiar, que, a su vez, produce un fuerte incremento de los nacimientos entre las mujeres de 
estas nacionalidades, y unos grupos infantiles (menores de 15 años) relativamente abultados en estos dos colectivos continentales. Si bien las distintas nacionalidades africanas ofrecen tasas de feminización homogéneas en torno a su media, entre las asiáticas no ocurre lo mismo, con extremos que van desde el 59\% para las filipinas al 14\% de las pakistaníes, con tasa casi equilibrada para los mayoritarios chinos.

La inmigración africana en España parece ser el grupo más estable entre los llegados por causas económico-laborales. Así, a los motivos de proximidad y menor renta en sus países de origen, se suma su aún escasa feminización, pero en rápido aumento, el crecimiento de su natalidad en España, y, sobre todo, el deseo mayoritario de estos inmigrantes que ya residen en España de traer a los familiares próximos y de permanecer definitivamente en España, tanto ellos mismos como, sobre todo, sus hijos, tal como explicitan las mujeres inmigradas que han sido encuestadas (Gozálvez y Equipo, 2008b). Según los datos del Censo de población de 2001, los inmigrados marroquíes en España, que son el colectivo nacional más numeroso (718.000 en 2009), son los que alcanzan mayor proporción como propietarios de su vivienda, lo que se suma a otros indicadores de estabilidad futura.

\section{LA FECUNDIDAD EN ESPAÑA: DIFERENCIAS Y SIMILITUDES ENTRE NACIONALES Y EXTRANJERAS}

Una retrospectiva reciente de la fecundidad en España nos muestra que ha experimentado un cambio tan novedoso como el de la llegada de la inmigración extranjera por motivos laborales. En efecto, en 1976 se inicia un cambio de tendencia que termina en un rápido hundimiento de la fecundidad, pues su mayor caída se produce durante los años 80 (fig. 4 y 5).

Esta disminución drástica de la natalidad y fecundidad podrá tener consecuencias económicas y demográficas problemáticas cuando las nuevas generaciones menguadas lleguen a la plena edad laboral y reproductora (Capel, 1997, 2001). En efecto, como se deduce de la pirámide de edades ofrecida en la fig. 3 , la tasa de envejecimiento demográfico cuenta con varios sumandos para crecer de modo acusado y sostenido, sobre todo a partir de 2025: a) por falta de efectivos debido a la persistente desnatalidad que se prolonga desde 1985, b) por la alta natalidad registrada en España durante el periodo 1955-1976, que llegarán a edad de jubilación a partir de 2020, c) por la importante agregación de población extranjera residente en España a las abultadas cohortes que actualmente tienen edad entre 45 y 20 años (fig. 3) y d) por el previsible aumento de la esperanza de vida -78 años para los varones, 84 para las mujeres, en 2008-.

Actualmente, por el contrario, el descenso de oferta de mano de obra joven por efecto de la desnatalidad se compensa por un rápido crecimiento tanto de la tasa de actividad de las mujeres españolas como por la llegada masiva de 
trabajadores-as extranjeros jóvenes, aunque la actual crisis económica transforme el mercado laboral en altas tasas de paro y aumenten las dificultades para la integración de la voluminosa y acelerada inmigración.

Figura 4. España. Evolución del número total de nacimientos (1975-2008), según la nacionalidad de la madre

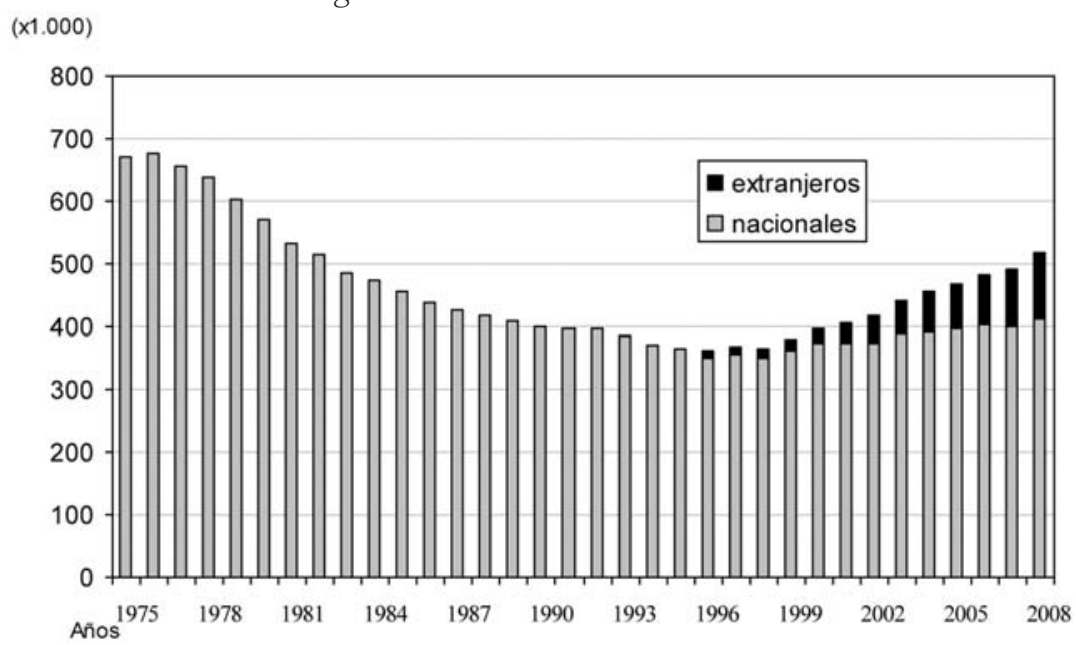

Fuente: INE, Movimiento natural de la población de España

Figura 5. España. Evolución del número medio de hijos por mujer (1975 a 2008)

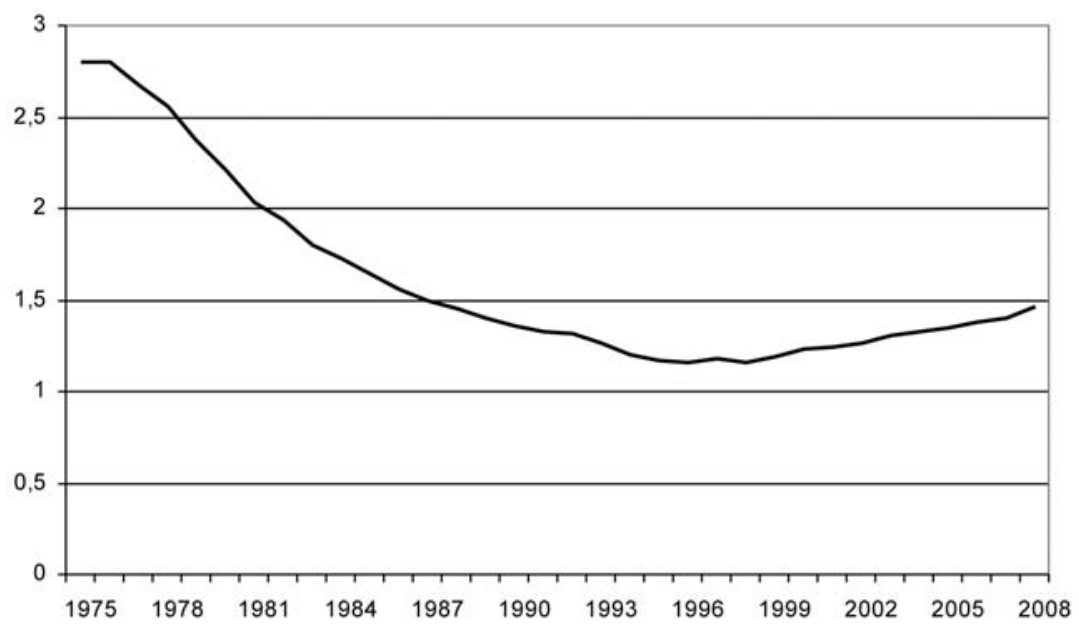

Fuente: INE, Movimiento natural de la población de España 
El rápido descenso de la natalidad-fecundidad en España se evidencia en los siguientes hitos: en 1976, la fecundidad se situaba en 2,80 hijos por mujer, y los nacimientos sumaban 677.456, mientras en 1990 estas cifras habían descendido a 1,36 hijos y 401.425 , respectivamente; el proceso toca fondo en 1998, con sólo 1,15 hijos por mujer, 365.193 nacimientos y un saldo natural para España de sólo 4.682 nuevos habitantes. Posteriormente, la fecundidad en España inicia una muy lenta recuperación, pues en 2008 sólo se ha conseguido 1,44 hijos por mujer (518.967 nacimientos), con lo que aún dista mucho de la recuperación suficiente (2,1 hijos por mujer), nivel que ya ha sido alcanzado en Francia y está muy próximo en toda la Europa septentrional -1,9 hijos por mujer en 2009-.

Como muestran las fig. 4 y 5 , la recuperación de los nacimientos y de la fecundidad en España coincide con el despegue de los nacimientos de madre extranjera (11.832 en 1996, 108.195 en 2008). Si restamos éstos a los nacimientos de madres españolas (fig. 4), queda patente el fuerte incremento de los primeros -acorde con las cifras absolutas de la joven inmigración- y el incremento muy suave de los nacimientos de madre española durante la última década.

La evolución más reciente de la fecundidad, entre 2005 y 2008, muestra un aumento generalizado, tanto en las españolas como en todas las nacionalidades de las extranjeras, así como en cada uno de los grupos de edades de las madres (cuadros 6 y 7). Por otra parte, según las tasas de fecundidad, en 2008 se diferencian en España dos grupos: uno con fecundidad insuficiente, formado por las mujeres españolas (1,36 hijos por mujer), las extranjeras europeas $(1,15)$ y las americanas $(1,41)$; en el grupo con fecundidad suficiente se sitúan las asiáticas $(2,37)$ y, sobre todo, las africanas $(3,76)$. No obstante, estos dos colectivos extranjeros con mayor fecundidad, y en menor medida las americanas, apenas si modifican al alza la fecundidad del total de mujeres que residen en España, pues el índice conjunto de españolas y extranjeras se sitúa en 1,44 hijos por mujer, es decir, las extranjeras sólo consiguen aumentar la fecundidad de las españolas en 0,08 hijos por mujer, aumento muy similar al que registran las madres inmigradas en Francia (Toulemon, 2004).

Las extranjeras que más podrían incrementar la fecundidad del conjunto de España, africanas y asiáticas, aún tienen censos muy reducidos: entre 15 y 49 años de edad se censan en España 11.764.264 mujeres en 2009, de las que son africanas 235.289 y asiáticas 82.519 . La gran diferencia de fecundidad entre las mujeres extranjeras, con mínima fecundidad en las europeas $(1,15)$, que son las más numerosas, y máxima fecundidad entre africanas $(3,76)$, escasas en cifras 
absolutas, se traduce en una fecundidad para el conjunto de las extranjeras aún muy insuficiente, pues sólo alcanza a 1,79 hijos por mujer en 2008, es decir, las extranjeras, en su conjunto, sólo superan en 0,43 hijos a las mujeres españolas $(1,36)$.

En conclusión, las tasas de fecundidad de las mujeres extranjeras que residen en España en 2008 responden, por un lado, a las fecundidades de sus países de origen, pero aminoradas por efecto de sus altas tasas de actividad en España y por la inseguridad laboral que conlleva su inmigración muy reciente y su frecuente situación irregular en sus actividades laborales (Gozálvez y Equipo, 2008b; Izquierdo, 2006), lo que se acentúa en los voluminosos colectivos que proceden de los países andinos de Latinoamérica, donde la fecundidad es sensiblemente más alta (3,5 hijos por mujer en Bolivia en 2009, 2,4 en Colombia, 2,8 en Ecuador) que la de las inmigradas en España desde esos países $(1,41)$. La alta fecundidad de las mujeres africanas es la excepción, pues su fecundidad en España $(3,76)$ se aproxima a la de sus países de origen, sobre todo si tenemos en cuenta que el $77 \%$ de estas mujeres son marroquíes, y, en este país, la fecundidad se sitúa en 2,4 hijos por mujer en 2009, mientras la fecundidad de los países subsaharianos se acerca a los 6 hijos por mujer. Las africanas que residen en España son las extranjeras con menores tasas de $\operatorname{actividad}^{2} \mathrm{y}$, sin duda, las más alejadas culturalmente, en su conjunto, de la sociedad española.

\subsection{Los calendarios de la fecundidad: retraso y concentración entre las mujeres españolas, y fecundidad temprana y repartida entre las extranjeras}

El fuerte descenso del número de hijos por mujer que se produce en España después de 1976 se acompaña de cambios sustanciales en las tasas de fecundidad por edades (fig. 6 y 7 , y cuadros 5 y 7 ).

2 Según el Censo de la Población de España de 2001, las tasas de actividad (sobre población de 16 y más años) de las mujeres extranjeras censadas oscilaba desde un $71 \%$ las americanas del sur y un $67 \%$ las europeas del Este, a un $42 \%$ las africanas, y, entre estas, las marroquíes, un $46 \%$. 
Cuadro 5. España, tasas de fecundidad (\%o) por edad de la madre, en 1981, 1991, 2001 y 2007

\begin{tabular}{|c|c|c|c|c|}
\hline Edad de la madre & 1981 & 1991 & 2001 & 2007 \\
\hline 15 & 3,48 & 1,66 & 1,96 & 2,38 \\
\hline 16 & 9,90 & 4,61 & 4,74 & 5,98 \\
\hline 17 & 19,82 & 9,80 & 8,70 & 11,87 \\
\hline 18 & 32,90 & 16,10 & 13,88 & 17,65 \\
\hline 19 & 49,63 & 22,47 & 18,08 & 24,57 \\
\hline 20 & 67,44 & 28,60 & 21,25 & 28,62 \\
\hline 21 & 87,76 & 35,31 & 23,09 & 31,16 \\
\hline 22 & 108,36 & 44,33 & 25,89 & 34,06 \\
\hline 23 & 127,74 & 54,60 & 28,68 & 36,91 \\
\hline 24 & 143,61 & 67,30 & 33,88 & 40,36 \\
\hline 25 & 146,99 & 82,03 & 41,33 & 46,34 \\
\hline 26 & 147,50 & 94,21 & 51,12 & 52,96 \\
\hline 27 & 141,95 & 104,63 & 63,29 & 61,32 \\
\hline 28 & 131,34 & 108,92 & 77,86 & 70,84 \\
\hline 29 & 126,66 & 107,96 & 90,26 & 83,11 \\
\hline 30 & 116,71 & 101,77 & 99,53 & 93,38 \\
\hline 31 & 92,46 & 89,32 & 102,16 & 99,93 \\
\hline 32 & 79,11 & 76,28 & 98,50 & 101,98 \\
\hline 33 & 73,06 & 63,47 & 93,00 & 99,46 \\
\hline 34 & 63,39 & 54,16 & 81,08 & 93,40 \\
\hline 35 & 54,14 & 42,77 & 70,44 & 85,69 \\
\hline 36 & 49,17 & 33,62 & 56,26 & 72,53 \\
\hline 37 & 40,46 & 26,46 & 41,83 & 55,38 \\
\hline 38 & 36,30 & 20,00 & 31,10 & 40,93 \\
\hline 39 & 29,61 & 15,29 & 22,09 & 30,88 \\
\hline 40 & 21,29 & 11,39 & 15,24 & 21,59 \\
\hline 41 & 20,49 & 7,71 & 9,44 & 13,54 \\
\hline 42 & 12,64 & 4,87 & 5,66 & 8,20 \\
\hline 43 & 7,66 & 3,25 & 3,19 & 5,01 \\
\hline 44 & 4,51 & 1,64 & 1,72 & 3,02 \\
\hline 45 & 2,67 & 0,92 & 0,90 & 1,78 \\
\hline 46 & 1,31 & 0,46 & 0,43 & 0,92 \\
\hline 47 & 0,73 & 0,20 & 0,21 & 0,51 \\
\hline 48 & 0,33 & 0,10 & 0,11 & 0,24 \\
\hline 49 & 0,22 & 0,08 & 0,11 & 0,13 \\
\hline
\end{tabular}

Fuente: INE, Movimiento natural de la población y Padrón municipal de habitantes 
Figura 6. España. Tasas (\%o) de fecundidad por edad (1981, 1991, 2001, 2007)

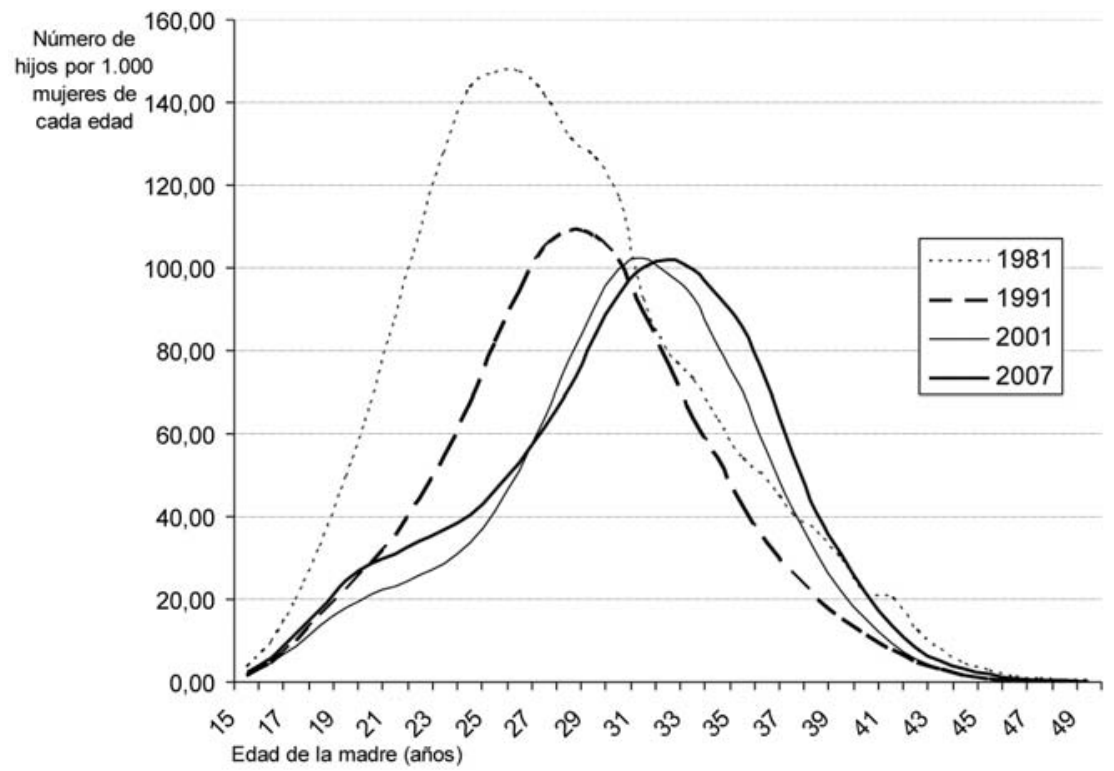

Figura 7. España (Tasas (\%o) de fecundidad por edad, según la nacionalidad de la madre, españolas y extranjeras, en 2005 y 2008

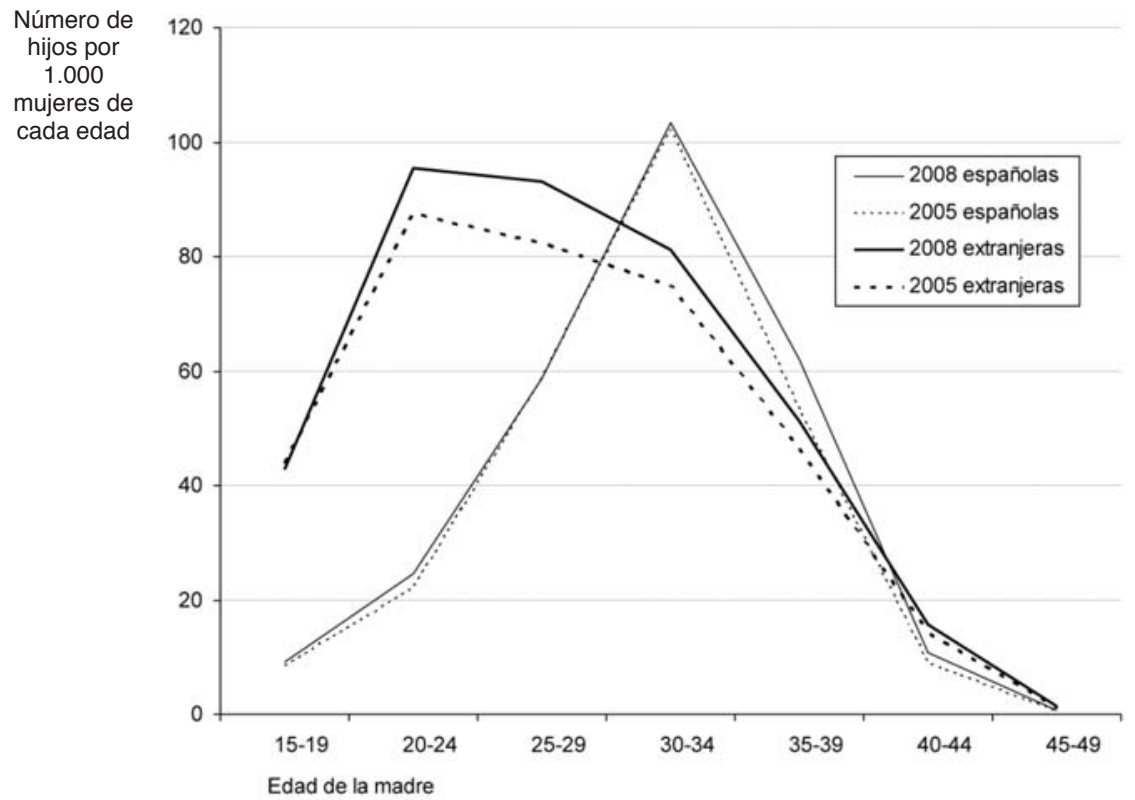


El periodo 1981-91 es el que registra mayores cambios, que afectan tanto al descenso de la fecundidad, sobre todo entre las mujeres menores de 30 años de edad, como a la distribución de las tasas por edad de la madre (cuadro 5 y fig. 6). Así, el número de hijos por mujer desciende de 2,04 a 1,33; en la fecundidad por edades, los mayores descensos se producen en las mujeres menores de 24 años, con reducciones que sobrepasan ampliamente la mitad en cada uno de los años (cuadro 5). La edad más fecunda, que en 1981 se situaba en los 26 años, con 147 hijos por 1.000 mujeres, en 1991 pasaba a los 28 años, con 109 hijos. Por su parte, las mujeres con más de 30 años de edad también generalizan su descenso de fecundidad, pero en cuantías mucho menores que las más jóvenes. En resumen, entre 1981 y 1991 los cambios mayores en la fecundidad por edades se producen hasta los 30 años, tanto con la reducción de las tasas como con el retraso de las edades más fértiles.

En la década 1991-2001 continúan produciéndose cambios sustanciales en la fecundidad de las mujeres españolas. El número de hijos por mujer, que en la década anterior había perdido -0,71, entre 1991 y 2001 permanece casi invariable. Por el contrario, el calendario de la fecundidad sí evoluciona mucho a favor de su retraso. Así, mientras en la década de 1981-91 el retraso afectaba sustancialmente a las mujeres menores de 30 años de edad, entre 1991 y 2001 el retraso afecta espectacularmente a todas las edades del periodo fértil, lo que supone, por una parte, que la fecundidad continúa disminuyendo mucho hasta los 30 años de edad, mientras la novedad se produce en el aumento de la fecundidad entre los 31 y 42 años de edad.

Finalmente, entre 2001 y 2007, la muy suave mejora de la fecundidad contrasta con cambios notables para las tasas por edades: a) aumenta de modo aparentemente novedoso la fecundidad entre los 15 y los 26 años de edad de la madre (cuadro 5), pero esto es debido sustancialmente al comportamiento de las madres extranjeras (fig. 7 y cuadro 7), aunque las españolas también aumentan muy ligeramente su fecundidad en estos grupos de edad; b) a partir de los 27 años de edad las mujeres continúan «envejeciendo» su fecundidad, primero disminuyendo sus tasas entre 27 y 31 años, y, desde los 32 años, incrementando las tasas, lo que evidencia la fecundidad cada vez más tardía de las españolas, ayudadas por las extranjeras a partir de los 40 años de edad (cuadro 7).

Las diferencias de la fecundidad por edades entre españolas y extranjeras (cuadro 7, fig. 7) muestran con claridad dos estadios de evolución en el proceso de desarrollo demográfico, aunque el índice coyuntural de fecundidad de los dos colectivos sea próximo en sus cifras globales muy bajas (1,36 y 1,79 para españolas y extranjeras, respectivamente). 
Cuadro 6. Año 2005 y 2008. España. Fecundidad según la nacionalidad de las madres, (mujeres de 15-49 años de edad)

\begin{tabular}{|c|c|c|c|c|c|c|c|}
\hline & \multicolumn{2}{|c|}{$\begin{array}{l}\text { Fecundidad general } \\
(\% \mathrm{o})\end{array}$} & \multicolumn{2}{|c|}{$\begin{array}{l}\text { Índice estandarizado } \\
\text { (indirecto)* }\end{array}$} & \multicolumn{2}{|c|}{ Hijos/mujer } & \multirow{2}{*}{$\begin{array}{c}\text { ICF } \\
\text { incremento, \% } \\
2005-2008\end{array}$} \\
\hline & 2005 & 2008 & 2005 & 2008 & 2005 & 2008 & \\
\hline $\begin{array}{l}\text { Total mujeres } \\
\text { España }\end{array}$ & 40,71 & 44,16 & 1,0 & 1,0 & 1,31 & 1,44 & 9,9 \\
\hline Españolas & 39,15 & 41,42 & & & 1,27 & 1,36 & 7,1 \\
\hline Europeas & 38,08 & 39,60 & 0,84 & 0,80 & $1,10^{* *}$ & 1,15 & 4,5 \\
\hline Africanas & 109,19 & 137,07 & 2,32 & 2,61 & $3,04 * *$ & 3,76 & 23,7 \\
\hline Americanas & 45,94 & 51,42 & 0,95 & 0,98 & $1,24 * *$ & 1,41 & 13,7 \\
\hline Asiáticas & 72,70 & 82,41 & 1,58 & 1,65 & $2,07^{* *}$ & 2,37 & 14,5 \\
\hline Total extranjeras & 52,42 & 59,00 & 1,11 & 1,16 & 1,59 & 1,79 & 12,6 \\
\hline
\end{tabular}

Fuente: Instituto Nacional de Estadística. Elaboración propia

$$
\text { * ief }=\frac{N^{i}}{\sum_{15-19}^{45-49}\left(f^{r} a^{*} F^{i} a\right)}
$$

$f^{r} a=$ fecundidad por edades del total de mujeres de España

$F^{i} a=$ mujeres extranjeras por edades

$\mathrm{N}^{\mathrm{i}}=$ total de nacimientos de las mujeres extranjeras

$* * i c f^{i}=i e f * i c f^{r}$

iefi $^{\mathrm{i}}$ índice estandarizado de fecundidad de las mujeres extranjeras

icf $^{\mathrm{r}}=$ índice coyuntural de fecundidad de las mujeres totales de España

Cuadro 7. Año 2005 y 2008. España. Tasas de fecundidad por edades de las madres (\%o)

\begin{tabular}{|c|c|c|c|c|c|c|c|c|c|c|}
\hline \multirow[t]{2}{*}{ Edad } & \multicolumn{2}{|c|}{$\begin{array}{l}\text { Total mujeres } \\
\text { que residen en } \\
\text { España }\end{array}$} & \multicolumn{2}{|c|}{ Extranjeras } & \multicolumn{2}{|c|}{$\%$ del ICF } & \multicolumn{2}{|c|}{ Españolas } & \multicolumn{2}{|c|}{$\%$ del ICF } \\
\hline & 2005 & 2008 & 2005 & 2008 & 2005 & 2008 & 2005 & 2008 & 2005 & 2008 \\
\hline $15-19$ & 11,29 & 13,17 & 39,31 & 40,99 & & & 8,53 & 9,17 & & \\
\hline $20-24$ & 30,97 & 38,06 & 81,57 & 91,66 & 38 & 37 & 22,96 & 25,42 & 12 & 13 \\
\hline $25-29$ & 62,46 & 67,51 & 74,19 & 88,64 & 23 & 25 & 60,25 & 61,60 & 24 & 22 \\
\hline $30-34$ & 96,45 & 98,19 & 67,30 & 74,15 & & & 101,11 & 103,57 & & \\
\hline $35-39$ & 51,67 & 59,39 & 41,44 & 47,67 & 34 & 34 & 53,01 & 61,46 & 61 & 61 \\
\hline $40-44$ & 9,06 & 11,12 & 12,91 & 14,30 & & & 8,67 & 10,68 & & \\
\hline $45-49$ & 0,46 & 0,71 & 1,11 & 1,22 & 5 & 4 & 0,41 & 0,66 & 3 & 4 \\
\hline $\begin{array}{l}\text { Hijos/ } \\
\text { mujer }\end{array}$ & 1,31 & 1,44 & 1,59 & 1,79 & 100 & 100 & 1,27 & 1,36 & 100 & 100 \\
\hline
\end{tabular}

Fuente: Instituto Nacional de Estadística. Elaboración propia 
En efecto, a los 24 años de edad, las españolas, en 2008, han proporcionado sólo el 13\% de su fecundidad total (1,36 hijos por mujer), mientras el conjunto de las extranjeras a esa edad ya ha producido el $37 \%$ sobre 1,79 hijos por mujer. La situación es inversa para las madres entre 30 y 39 años de edad: las extranjeras en estas edades concentran el 34\% de su fecundidad total, frente al 61 por ciento de las españolas. Las curvas de la fig. 7 muestran este comportamiento dispar del calendario de fecundidad: muy temprano entre las extranjeras y una fecundidad ya muy tardía entre las españolas. La fecundidad temprana de las extranjeras responde a que continúan con los calendarios de sus países de origen, dado lo reciente de su inmigración a España. Se representan dos curvas para cada colectivo, que están separadas por sólo tres años, pero muestran evolución notable: la fecundidad aumenta en 2008, sobre todo entre las extranjeras. Las diferencias en los calendarios de la fecundidad de ambos colectivos, españolas y extranjeras, son múltiples: además de la mayor fecundidad temprana y tardía entre las extranjeras, los grupos de edad con mayor fecundidad aparecen como los más divergentes; así, las españolas tienen una fortísima concentración de su fecundidad en el grupo 30-34 años, con 104 nacimientos por 1.000 mujeres, mientras el máximo de fecundidad para las extranjeras es más temprano y menos concentrado, es decir, la tasa máxima es la del grupo 20-24 años, con 92 hijos por 1.000 mujeres, pero el grupo 25-29 es el que más ha aumentado su fecundidad entre 2005-2008 (89 hijos por 1.000 mujeres), sin duda reflejo de su inicial adaptación a una fecundidad más tardía, propia de las españolas. En este sentido, el carácter reciente de esta inmigración quedaría reflejado en su fecundidad repartida a lo largo de la edad fértil, propia de los países de origen, que contrasta con la fecundidad de las españolas, caracterizada por su alta concentración en el grupo 30-34 años de edad, fruto de los retrasos -matrimonios tardíos, adaptación a las exigencias laborales de la mujer...-casi hasta el límite de las posibilidades que ofrece su fertilidad.

El aumento de fecundidad en las extranjeras que residen en España, patente en las estadísticas de 2005 y 2008, tanto en la fecundidad general de cada origen geográfico como en la fecundidad por edades (cuadro 6 y 7), es un hecho que podría ser coyuntural y relacionado con la juventud de estos colectivos de reciente inmigración. Cuando las inmigrantes proceden de países con fecundidad más alta -todos los orígenes no europeos- que la del país de acogida, lo habitual es que las mujeres inmigradas reduzcan su fecundidad de acuerdo al de su nuevo entorno (Toulemon, 2004; Bélanger, 2009; Izquierdo, 2006).

Por otra parte, esta reducción habitual de fecundidad en las mujeres inmigradas queda confirmada en las encuestas que se han realizado a las africanas y latinoamericanas que residen en España, cuando se les pide opinión específica 
sobre la fecundidad que desean para sí mismas y la que desean para sus hijas. Así, las africanas que residen en España -70\% magrebíes, 30\% subsaharianas, entre las que tienen 15-49 años de edad-, en 2005 tienen una fecundidad aproximada de 3,04 hijos por mujer (cuadro 6), mientras en sus países de origen la fecundidad estimada (INED, 2005) es de 2,5 hijos en Marruecos y Argelia y en torno a 5,9 en los países subsaharianos. En los países de América del Sur con más inmigradas en España, la fecundidad de la misma fecha oscila entre 3,3 en Ecuador y 2,4 en Argentina.

En cuanto a las mujeres africanas y latinoamericanas residentes en la España mediterránea -desde Girona a Almería- y encuestadas en 2003-2005³, el número de hijos que desean para sí mismas y para sus hijas es el siguientet.

\begin{tabular}{|l|r|r|r|r|r|}
\cline { 2 - 7 } \multicolumn{1}{c|}{} & \multicolumn{4}{c|}{ Número de hijos deseados para sí y para sus hijas (en \%) } \\
\hline Mujeres encuestadas & Ninguno & 1 hijo & 2 hijos & 3 hijos & 4 o más \\
\hline Magrebíes & & 12 & 46 & 24 & 18 \\
\hline Subsaharianas & & 6 & 26 & 42 & 26 \\
\hline Latinoamericanas & & 18 & 42 & 26 & 13 \\
\hline Para hijas de africanas & 2 & 8 & 54 & 22 & 14 \\
\hline Para hijas de latinoamericanas & 3 & 18 & 60 & 13 & 6 \\
\hline
\end{tabular}

Las proporciones indicadas muestran con claridad la fractura existente entre las africanas del norte y las del sur del Sáhara, que responde a la fecundidad existente en sus países de origen: tres o más hijos son deseados por más de dos tercios de las subsaharianas, mientras la proporción baja al 42 en las magrebíes y al 39 en las latinoamericanas; asimismo, el deseo de hijo único, o incluso los dos hijos, también subraya las mismas diferencias entre los tres colectivos. Por otra parte, queda manifiesta la «proximidad» de magrebíes y latinoamericanas en sus deseos de fecundidad, centrada en los dos hijos, mientras las subsaharianas todavía desean fecundidad mucho mayor, centrada en los tres hijos y, como segunda opción, 4 o más hijos. Cuando ambos colectivos, africanas y latinoamericanas, manifiestan

3 Proyecto La inmigración femenina (africana y latinoamericana) en la España mediterránea, Ref. BSO2002-00229, financiado por Ministerio de Ciencia y Tecnología. Investigador principal, Vicente Gozálvez Pérez.

4 Pregunta: «Número de hijos que desea tener usted»: Respondieron 177 mujeres magrebíes, 31 subsaharianas y 196 latinoamericanas.

Pregunta: «Si la inmigrante tiene, o tuviera, hijas, ¿cuál sería el número ideal de hijos que desearía para ellas?». Respondieron 215 mujeres magrebíes, 61 subsaharianas y 287 latinoamericanas. 
sus deseos de fecundidad para sus hijas, la fecundidad se reduce ostensiblemente y se centra en los dos hijos, aunque existen claras diferencias en los deseos de alcanzar familias numerosas, más altos entre las africanas, lo que es acorde con las diferencias que emanan de sus distintas culturas, de sus diferentes niveles de instrucción y de sus grados de segregación-integración en la sociedad española.

\subsection{Acelerado incremento de los nacimientos de madre extranjera}

Los nacimientos de madre extranjera en el país de acogida, cuando son abundantes, conllevan estabilidad de las colonias extranjeras, pues suelen ser fruto de reagrupación familiar, suelen facilitar una mayor integración de los inmigrados en la sociedad española y también aumentan las colonias extranjeras por saldo natural. Por otra parte, estos nacimientos, que, en el caso de España, han experimentado un fuerte incremento durante la última década (fig. 4), contribuyen a restaurar el desequilibrio que la desnatalidad española ha introducido en el grupo joven de la pirámide de edades (fig. 3). El aumento reciente del número de nacimientos de madre extranjera es consecuencia de una estructura muy joven de las madres extranjeras y de su inmigración masiva durante la última década (fig. 1).

En efecto, en 1996 nacieron en España 11.832 niños de madre extranjera, que representaron el 3,3\% del total de nacidos en el país (362.636), mientras en 2008 estas cifras han alcanzado 108.195 nacimientos y el 20,8\% del total de nacidos en España (518.967), aunque los extranjeros representan el 12,1\% de la población total de España. Estas diferentes proporciones de los extranjeros en los totales de la población y de los nacimientos se explican por una estructura por edad de las extranjeras más favorable a la natalidad: las mujeres extranjeras entre 15 y 39 años de edad son el 54,3 por ciento de su total, mientras en el total de mujeres empadronadas en España a 1-01-2009, las de este grupo de edades sólo representan el 34,7 por ciento.

El desigual reparto geográfico de los extranjeros en España (fig. 2) tiene fiel reflejo en la distribución territorial de sus nacimientos, tal como se muestra en el cuadro 8: ocho comunidades autónomas superan la media relativa nacional (20,8 por ciento de los nacimientos en 2008 son de madre extranjera), encabezadas por Baleares (31,8\%), La Rioja $(29,6)$, Cataluña $(28,2)$, Madrid $(27,1)$ y Murcia $(26,1)$. En cifras absolutas, destacan los nacimientos de madre extranjera localizados en Cataluña y en Madrid, que suman 46.477 o el 43 por ciento de su total nacional, mientras su población extranjera representa el 40\%; si en Cataluña el colectivo que más hijos produce es el africano ( $40 \%$ de su total de nacimientos de madre extranjera), seguido por el de madres americanas (32) y europeas (18), en Madrid, el reparto de los nacimientos de madre extranjera está más polarizado a favor de las americanas, que dan casi la mitad del total, mientras el resto está más equilibrado entre las europeas (26\%), sobre todo rumanas, y las africanas (18). 
Cuadro 8. Nacidos de madre extranjera por comunidades autónomas de España, y su porcentaje del total de nacidos en la región

\begin{tabular}{|c|c|c|c|c|c|c|}
\hline \multirow{2}{*}{ Comunidad } & \multicolumn{2}{|c|}{2008} & \multicolumn{2}{|c|}{2005} & \multicolumn{2}{|c|}{2002} \\
\hline & nacidos & $\%$ & nacidos & $\%$ & nacidos & $\%$ \\
\hline Baleares & 4.037 & 31,8 & 2.631 & 24,1 & 1.882 & 18,2 \\
\hline La Rioja & 1.041 & 29,6 & 686 & 22,6 & 342 & 13,5 \\
\hline Cataluña & 25.132 & 28,2 & 16.621 & 20,8 & 9.564 & 14,0 \\
\hline Madrid & 21.345 & 27,1 & 14.701 & 21,2 & 10.884 & 17,2 \\
\hline Murcia & 5.061 & 26,1 & 3.461 & 20,0 & 2.338 & 15,1 \\
\hline Aragón & 3.473 & 25,4 & 1.890 & 16,3 & 1.101 & 10,6 \\
\hline C. Valenciana & 13.565 & 23,8 & 8.811 & 17,4 & 4.917 & 11,2 \\
\hline Navarra & 1.466 & 20,9 & 952 & 15,5 & 641 & 11,0 \\
\hline España & 108.195 & 20,8 & 70.259 & 15,1 & 43.469 & 10,4 \\
\hline Castilla-La Mancha & 4.776 & 20,7 & 2.427 & 12,8 & 1.144 & 6,9 \\
\hline Canarias & 3.855 & 18,6 & 2.882 & 14,3 & 2.129 & 11,2 \\
\hline Castilla y León & 3.299 & 15,5 & 1.851 & 9,5 & 1.044 & 5,8 \\
\hline País Vasco & 3.039 & 14,3 & 1.528 & 7,8 & 808 & 4,4 \\
\hline Andalucía & 12.319 & 12,3 & 7.408 & 8,1 & 4.246 & 5,2 \\
\hline Cantabria & 692 & 11,8 & 386 & 7,3 & 235 & 5,2 \\
\hline Asturias & 763 & 9,3 & 506 & 6,8 & 284 & 4,2 \\
\hline Galicia & 1.794 & 7,7 & 1.229 & 5,8 & 782 & 4,0 \\
\hline Extremadura & 453 & 6,2 & 495 & 5,0 & 324 & 3,3 \\
\hline Melilla & 221 & 19,0 & 333 & 32,9 & 543 & 44,9 \\
\hline Ceuta & 753 & 7,0 & 133 & 12,5 & 262 & 24,8 \\
\hline
\end{tabular}

Fuente: Instituto Nacional de Estadística: Movimiento Natural de la Población

En 2008, los nacimientos de madres marroquíes, 25.437, destacan sobre cualquier otra nacionalidad, pues le siguen a mucha distancia los nacimientos de rumanas, 13.631, colonia femenina mucho más numerosa que la marroquí -entre 20 y 39 años de edad en 2009, residen en España 130.006 mujeres marroquíes, y 217.871 rumanas-. Estos nacimientos tan dispares en relación con el número de posibles madres, se explican, ante todo, por la mayor fecundidad de las marroquíes, pero también por su mayor antigüedad y estabilidad en España. Los nacimientos de madres americanas continúan siendo los más numerosos -39.576 en 2008-, a resultas del mayor censo de mujeres con la mejor edad para ser madres -552.523 mujeres entre 20 y 39 años de edad-, pero la primacía sobre los nacimientos de madres africanas se recorta con celeridad. No obstante, el comportamiento inmigratorio y en nacimientos 
de los principales países latinoamericanos de inmigración en España es dispar en los últimos años (cuadro 3 y 9): los ecuatorianos residentes en España -la colonia más numerosa de este continente- han disminuido su número, igual que los argentinos, y los colombianos -segunda colonia- han permanecido casi estables; tales comportamientos inmigratorios se reflejan en el número de nacimientos con madres de estas nacionalidades, pues en los tres casos han permanecido estables durante los últimos años. Por el contrario, la inmigración desde Bolivia y Brasil ha crecido mucho en los últimos tres años (+19\% anual), lo que se refleja con creces en los nacimientos de madres de estos países, con crecimientos anuales de $24 \%$ y $28 \%$, respectivamente. Así, pues, la fecundidad y la dinámica de los flujos de las diferentes colonias de extranjeros explican bien la evolución reciente de su número de nacimientos en España.

Cuadro 9. España. Nacimientos de madre extranjera, según nacionalidad

\begin{tabular}{|c|c|c|c|c|c|}
\hline \multirow[t]{2}{*}{ País } & \multicolumn{5}{|c|}{ Años } \\
\hline & 2008 & 2007 & 2006 & 2004 & 2002 \\
\hline Marruecos & 25.437 & 20.165 & 17.327 & 13.016 & 8.735 \\
\hline Rumanía & 13.631 & 11.590 & 8.775 & 5.042 & 2.002 \\
\hline Ecuador & 9.548 & 9.348 & 9.088 & 11.100 & 8.273 \\
\hline Bolivia & 6.508 & 6.476 & 4.207 & 1.796 & 477 \\
\hline Colombia & 5.388 & 5.115 & 4.770 & 4.926 & 4.832 \\
\hline China & 4.531 & 3.689 & 2.977 & 2.385 & 1.553 \\
\hline Brasil & 3.206 & 2.634 & 1.956 & 1.132 & 724 \\
\hline Argentina & 2.531 & 2.553 & 2.451 & 2.102 & 1.360 \\
\hline Perú & 2.461 & 2.061 & 1.886 & 1.299 & 888 \\
\hline Bulgaria & 1.947 & 1.681 & 1.373 & 941 & 443 \\
\hline R. Dominicana & 1.934 & 1.652 & 1.418 & 936 & 804 \\
\hline R. Unido & 1.744 & 1.679 & 1.683 & 1.422 & 1.110 \\
\hline Francia & 1.320 & 1.179 & 1.227 & 1.024 & 926 \\
\hline América & 39.576 & 36.211 & 31.020 & 27.154 & 19.852 \\
\hline África & 32.252 & 25.867 & 22.433 & 16.695 & 11.337 \\
\hline Europa & 29.487 & 25.729 & 21.628 & 15.079 & 9.694 \\
\hline Asia & 6.800 & 5.638 & 4.780 & 3.675 & 2.555 \\
\hline Oceanía & & & & 30 & 31 \\
\hline Total & 108.195 & 93.486 & 79.903 & 62.633 & 43.469 \\
\hline $\begin{array}{l}\% \text { Total de } \\
\text { nacidos }\end{array}$ & 20,8 & 19,0 & 16,5 & 13,8 & 10,4 \\
\hline
\end{tabular}

Fuente: Instituto Nacional de Estadística: Movimiento Natural de la Población 


\section{LOS TRABAJADORES EXTRANJEROS: DESDE EL EMPLEO DE SUSTITUCIÓN POR MOTIVOS DEMOGRÁFICOS Y SOCIALES A INDICADOR DE INTEGRACIÓN}

Los trabajadores extranjeros procedentes de países menos desarrollados, por su elevado volumen y por su «especificidad laboral»-con frecuencia impuesta por la imposibilidad de ocupar trabajos menos duros o social y económicamente más apetecidos-, pueden contribuir a solventar insuficiencias de la mano de obra nacional. Sin embargo, también son un colectivo especialmente desfavorecido cuando aumenta el paro laboral, y, con ello, se agravan las dificultades para su integración en la sociedad española.

En efecto, entre las posibles insuficiencias de la mano de obra nacional destacan:

a) Las que se originan en la actual estructura por edades de España (fig. 3), sobre todo por la brusca disminución del grupo joven, futuros trabajadores, con relación a las abultadas cohortes de adultos; esta futura carestía de mano de obra nacional está provocada por la desnatalidad en España durante los últimos treinta años. Por otra parte, el aumento de la vida media en España, junto con la alta natalidad antes de 1935, crea actualmente una abultada población mayor de 70 años de edad, que, sin duda, requiere «cuidadores» que sustituyan a la «mano de obra familiar», cada vez menos disponible por el aumento de la tasa de actividad femenina. Los empleados de hogar en España son precisamente el nicho de empleo más especializado en extranjeros (Gozálvez, 2008c), además de aumentar sus cifras absolutas, pese a la actual crisis económico-laboral.

b) Necesidad de trabajadores extranjeros que sustituyan a los trabajadores nacionales, que suelen rechazar determinados empleos, como los del sector agrario; éstos, además de su dureza, exigen movilidad geográfica de la mano de obra, derivada tanto del minifundismo de las explotaciones como de la concentración laboral durante el ciclo de los cultivos (Gozálvez, López Trigal, 1999; Capel, 2001).

Por el contrario, en situaciones de crisis económica-laboral, como la actual, los trabajadores extranjeros no cualificados llegados recientemente, y/o con dificultades en el manejo de la lengua local, son, sin duda, los más afectados negativamente, tal como era anunciado por los empleadores de extranjeros encuestados en la España mediterránea durante 2003-2005 (Gozálvez y Equipo, 2006b). Así, en aquellos años, ante una hipotética reducción de empleo en las empresas de estos empleadores encuestados, el 41\% afirmaba que los trabajadores extranjeros estarían más afectados que los trabajadores 
nacionales, debido a la preferencia de los empresarios por la mano de obra nacional (40\%) y a la menor antigüedad en la empresa de los inmigrados (31\%). Además, el conocimiento de la lengua local, según el 88\% de los empresarios encuestados, es determinante (36\% de los empresarios) o importa bastante (52\%) en la contratación de mujeres extranjeras, lo que afecta especialmente al colectivo africano.

Así, pues, los empleos de los extranjeros procedentes de países menos desarrollados, en elevada proporción es -y sobre todo será- empleo de sustitución demográfica de trabajadores nacionales (Bélanger, 2009), aunque actualmente es mucho más frecuente el empleo de sustitución por motivos sociales, es decir, los extranjeros ocupan trabajos que rechazan los trabajadores nacionales, como el trabajo en el sector agrario, en el hogar o en los niveles menos cualificados de la hostelería.

Los extranjeros en situación irregular son una «característica» que se ha «endemizado» en España (Capel, 2001; Gozálvez y otros, 1995), pues continúa afectando a muchos de los que proceden de países menos desarrollados, a pesar de las repetidas regularizaciones extraordinarias que el Gobierno de España ha realizado desde 1985. Así, a 31-12-2008, los extranjeros que tienen certificado de registro o tarjeta de residencia (regularizados) suman 4.473.499 (Ministerio de Trabajo e Inmigración, 2009), mientras que los extranjeros contabilizados en el Padrón de Habitantes (regularizados e irregulares) a 1-01-2009 son 5.648.671, es decir, la diferencia entre ambas fuentes estadísticas oficiales, entendida como extranjeros en situación irregular, es de 1,2 millones o el 26,3\% del total de extranjeros empadronados. Esta condición de situación irregular, origen de discriminaciones múltiples, puede alcanzar mayor grado entre los trabajadores extranjeros.

En efecto, en abril de 2010 (Ministerio de Trabajo, 2010), los trabajadores extranjeros afiliados a la Seguridad Social y en alta laboral (regularizados) ascienden a 1.846.694 o el 10,5\% del total de trabajadores de España en esa situación, mientras los extranjeros activos estimados por la Encuesta de Población Activa en el primer trimestre de 2010 son 3.674 .700 o el 16\% del total de España, y los ocupados 2.543.300, es decir un 38\% más que los afiliados a la Seguridad Social y en alta laboral. Según la EPA, la tasa de paro laboral asciende al 30,8\% de los activos extranjeros, mientras esta tasa para el conjunto de España es del 20,0\%.

Según la encuesta realizada a los empresarios que emplean mujeres extranjeras (Gozálvez y Equipo, 2006b), el 42\% afirma que la situación irregular de éstas con mucha frecuencia repercute en su discriminación salarial respecto a las que se encuentran en situación legal en España, pero esta discriminación 
sube al 59\% según los empresarios agrícolas. Además, el sector agrario, en la situación actual de crisis, refuerza su carácter de sector «refugio» para el empleo: así, en abril de 2007 los extranjeros empleados en el sector agrario afiliados a la Seguridad Social y en alta laboral eran 171.554 (entre un total de 1.947 .992 trabajadores extranjeros), mientras en abril de 2010 son 270.753 (de un total de 1.846.694). La misma evolución positiva de empleo, aunque en menor cuantía, han seguido otros sectores donde los extranjeros encuentran «nichos» de empleo, como los empleados de hogar (164.754 en 2007, 185.853 en 2010), en hostelería (245.787 y 297.154, respectivamente) y en comercio (196.125 y 252.080, respectivamente). Por el contrario, los trabajadores extranjeros han disminuido en las ramas de actividad más afectadas por la crisis y/o con mayor competencia con los trabajadores nacionales, como es la industria (152.687 en 2007 y 133.421 en 2010) y, sobre todo, en la construcción, de 403.462 extranjeros afiliados a la Seguridad Social en abril de 2007, a 212.102 en abril de 2010. Asimismo, son «parlantes» las cifras totales: las tasas de trabajadores extranjeros afiliados a la Seguridad Social, respecto al total de extranjeros residentes, era del $43,1 \%$ en abril de 2007 (respecto a los residentes a 1-01-2007) y del 32,7\% en abril de 2010.

Según las encuestas realizadas a trabajadores extranjeros en la España mediterránea (entre Girona y Almería), el empleo irregular o no regularizado es la norma para los recién llegados (Gozálvez y Equipo, 2008a y 2006a), singularmente en los sectores con más empleo extranjero: construcción, trabajadores del hogar, hostelería y agricultura. En efecto, los 691.656 trabajadores extranjeros en situación irregular que solicitaron regularización entre el 7 de febrero y el 7 de mayo de 2005 se distribuían fundamentalmente en el trabajo en el hogar con el 31,8\% del total, en la construcción (20,7\%), agricultura (15\%) y hostelería $(10,3 \%)$ (Ministerio de Trabajo y AA.SS.). Es decir, estas cuatro ramas suman el 78 por ciento de los trabajadores extranjeros en situación irregular en 2005, mientras, entre los afiliados a la Seguridad Social y en alta laboral en 2010, sobrepasan en poco la mitad de todos ellos. Ante esta situación, unida al comportamiento del empleo extranjero en estas ramas entre abril de 2007 y abril de 2010, es presumible un aumento paralelo de la irregularidad laboral, especialmente en la agricultura y en los trabajadores del hogar. Así, pues, las discriminaciones laborales que pueden afectar a los extranjeros, siempre con evidentes repercusiones negativas en sus procesos de integración en la sociedad española, son variadas y graves, no tanto por las relaciones entre los trabajadores nacionales y extranjeros, sino por las consecuencias derivadas de su inicial situación de irregularidad, que repercute en su inestabilidad laboral y recortes salariales, tal como han declarado los empresarios que emplean a extranjeros. 


\section{CONCLUSIONES}

Los voluminosos flujos y stock alcanzados por los inmigrados extranjeros que ha recibido España durante la última década han sido inesperados para el entorno económico-laboral que ofrece el país, pero sí deberían haber sido previstos debido al desarrollo insuficiente de los países de origen, a lo que se suma la debilidad relativa de las fronteras de España a esta inmigración, y los efectos de la globalización, entre otros factores. Los problemas sociales y de integración de los inmigrantes que pudieran provocar tanto la rapidez con que se ha producido este proceso inmigratorio como el deficiente contexto económico-laboral que ofrece España cuentan, no obstante, con un «amortiguador». En efecto, pese a la diversidad de orígenes de los extranjeros que llegan a España por necesidades económico-laborales, el balance de estos flujos es muy favorable a las comunidades extranjeras mejor aceptadas por los españoles, es decir, los latinoamericanos y los europeos, que suman 3,1 millones o el 70\% de todos los extranjeros que proceden de países menos desarrollados.

La primera aportación de los extranjeros a la población total de España es el incremento demográfico del país, con tasas nunca alcanzadas anteriormente. Además, esta inmigración es prácticamente la única variable que interviene en dicho incremento, pues el saldo natural ofrece cifras testimoniales o próximas a cero. El incremento demográfico de España por saldo inmigratorio es una novedad histórica, pues, antes de iniciarse este proceso inmigratorio, el incremento demográfico del país era deudor sólo del propio saldo natural, que se repartía entre el incremento demográfico de España y la alimentación de su saldo emigratorio, históricamente negativo para España.

La segunda y más importante aportación de los extranjeros a la demografía de España es el rejuvenecimiento demográfico actual, tanto por la juventud de los llegados como por su alta participación en los nacimientos que se producen en el país. Este rejuvenecimiento pudiera ser muy positivo a medio y largo plazo si persiste la desnatalidad actual y si se supera con éxito el proceso de integración de los inmigrantes, especialmente de sus hijos. Los 4,4 millones de extranjeros procedentes de países menos desarrollados se concentran en un $77 \%$ entre los 0 y 39 años de edad, frente al 51\% del total de la población de España. Este rejuvenecimiento demográfico puede prolongarse en el tiempo si el mercado laboral se normaliza; así, la llegada de inmigrantes jóvenes, su reagrupación familiar y su creciente participación en los nacimientos que se producen en España suman en el mismo sentido. Por otra parte, la reagrupación familiar, tanto de familias ya constituidas en los países de origen como por inmigración de mujeres por motivos matrimoniales, puede tener mayor incremento relativo entre los africanos y asiáticos, pues son los colectivos más alejados culturalmente de la población 
autóctona, y, además, son los extranjeros con menores tasas de mujeres inmigradas $-35 \%$ y $38 \%$, respectivamente-, y los que proporcionan la fecundidad más alta entre los extranjeros.

No obstante, tampoco se puede olvidar que los inmigrados en España también envejecerán y podrán acelerar el envejecimiento de España a partir de 2025, tal como se deduce de la actual pirámide demográfica; en este sentido, su aporte a la natalidad también podrá disminuir.

Los dos millones de trabajadores procedentes de países menos desarrollados puedenn tener, en la actual situación de crisis, efectos con valoraciones de distinto signo. Las cuantiosas llegadas que se han producido durante la última década, mayoritariamente han ocupado empleos poco apetecidos o rechazados por los trabajadores nacionales, sin olvidar que dichos empleos también son rechazados o no apetecidos por los propios inmigrantes, según manifiestan en las encuestas, como los trabajos en el sector agrario, los trabajos en el hogar generados por el envejecimiento de los españoles o los empleos menos apetecidos de la hostelería; también han ocupado cuantiosos empleos en la construcción, en unos años de crecimiento desbordante del sector. En cualquier caso, el trabajo irregular $-y$ por tanto sujeto a discriminaciones- ha sido muy frecuente, al menos durante la primera etapa en España de estos trabajadores extranjeros. A medio plazo, parece que los trabajadores extranjeros que se han iniciado como sustitución laboral social podrían continuar reconvertidos en trabajadores de sustitución demográfica, debido a la drástica reducción de los nacimientos en España durante los últimos treinta años, que en su momento podrá generar escasez de mano de obra nacional.

Por otra parte, los aportes de la población extranjera a la demografía de España pueden tener contrapartidas problemáticas, como es su integración en la sociedad española, sobre todo entre los que tienen culturas más alejadas de la autóctona, situación que pueden padecer tanto los llegados ya adultos como su población infantil, futuros ciudadanos y trabajadores en España. Especial atención merecen las discriminaciones laborales, por sus múltiples repercusiones negativas.

Pese a las dificultades creadas por la crisis económica actual, la continuidad de los flujos de inmigración parece asegurada, pues permanecen las causas económicas, demográficas y políticas que provocan la «expulsión» de trabajadores jóvenes desde sus países de origen, factor que, sin duda, es más decisivo en su decisión de emigrar que las dificultades que encuentran estos inmigrantes en los países de destino. Además, la continuidad de estos flujos encuentra apoyo en el reforzamiento de los lazos entre ambos extremos de estos flujos migratorios, es decir, entre los ya inmigrados en España y sus familiares y amigos que residen en sus países de origen, pero que son potenciales candidatos a la emigración. 
Las desigualdades extremas de desarrollo entre países, las «debilidades» fronterizas de España o las nuevas lógicas migratorias de la globalización, entre otros aspectos, continuarán produciendo migraciones internacionales no deseadas y/o forzadas, y por tanto conflictivas. Por ello es necesario potenciar acciones, políticas migratorias y estudios que conduzcan a un mejor conocimiento de los flujos migratorios internacionales, para, así, incentivar políticas de desarrollo eficaces que aminoren progresivamente las migraciones internacionales forzadas y conflictivas. En cualquier caso, la eficacia de estas políticas de desarrollo también depende en alto grado del apoyo y viabilidad que les proporcionen los dirigentes de los países menos desarrollados.

\section{BIBLIOGRAFÍA}

BAyOna i CARRASCo, J. (2007): «La segregación residencial de la población extranjera en Barcelona: ¿una segregación fragmentada?», Scripta Nova. Revista electrónica de Geografía y Ciencias Sociales, vol. XI, núm. 235.

BÉLAnger, A. (2009): «Une analyse provinciale de la migration de remplacement au Canada», Cahiers québécois de démographie, vol. 39, nº 1, pp.71-104.

Capel, H. (1997): «Los inmigrantes en la ciudad. Crecimiento económico, innovación y conflicto social», Scripta Nova. Revista electrónica de Geografía y Ciencias Sociales, $\mathrm{n}^{\circ} 3,24 \mathrm{p}$.

CAPEl, H. (2001): «Inmigrantes extranjeros en España. El derecho a la movilidad y los conflictos de la adaptación: grandes expectativas y duras realidades», Scripta Nova. Revista Electrónica de Geografía y Ciencias Sociales, nº 81, 31 p.

Cutillas OrgilÉs, E. (2006): «El incremento de la población extranjera en la provincia de Alicante. Los contrastes en su distribución espacial», Investigaciones geográficas, no 41, pp. 85-104.

Dewitte, Ph., (Dir.) (1999): Immigration et intégration, l'état des savoirs, Paris, Ed. La Découverte.

Díez Nicolás, J. (2002): «Las dos caras de la Inmigración», en Eiras Roel, A. y GonzÁlez Lopo, D. L. (Coord.): Movilidad interna y migraciones intraeuropeas en la Península Ibérica, Universidad de Santiago de Compostela, pp. 235-257.

Domingo, A.; López-Falcón, D.; Bayona y Carrasco, J. (2010): «Reagrupación familiar en la provincia de Barcelona, 2004-2008», Migraciones, n 27, pp. 11-47.

Dumond, G. F. (2006): «Las nuevas lógicas migratorias», en GozÁlvez Pérez, V. (edit.): La inmigración extranjera como desafío y esperanza, Universidad de Alicante, Departamento de Geografía Humana, pp. 13-26.

GozÁlvez PÉREZ, V. (Dir.) (1995): Inmigrantes marroquíes y senegaleses en la España mediterránea, Generalitat Valenciana, Conselleria de Treball i Afers Socials, $442 \mathrm{p}$. 
GozÁlvez Pérez, V. y Equipo (2005): «La inmigración extranjera en España: aumento exponencial, diversificación geográfica y posibilidades de integración», en Di Comité, L.; Rodríguez Rodríguez, V.; Girone, S.: Sviluppo demografico e mobilità territoriale delle popolazioni nell'area del Mediterraneo: Italia e Spagna, due Paesi a confronto, Quaderni 32, Bari, Università degli Studi di Bari, Dipartimento per lo Studio delle società mediterranee, pp. 147-178.

Gozálvez Pérez, V. y Equipo (2006a): «Los indicadores de integración de los inmigrantes en España», en GozÁlvez Pérez, V. (Coord.): La inmigración extranjera como desafío y esperanza, Universidad de Alicante, Departamento de Geografía Humana, pp. 41-58.

GozÁlvez Pérez, V. y Equipo (2006b): «Las trabajadoras extranjeras en la España mediterránea. La perspectiva empresarial», Estudios Geográficos, vol. LXVII, no 261, pp. 523-547.

Gozálvez Pérez, V. y Equipo (2008a): «La diversificación de los extranjeros en España: sus implicaciones», en Di Comité, L.; Garavello, O.; Galizia, F.: Sviluppo demografico ed economico nel Mediterraneo, Quaderni 35, Bari, Università degli Studi di Bari, Dipartimento per lo Studio delle società mediterranee, pp. 151-184.

GozÁlvez Pérez, V. y Equipo (2008b): «Mujeres africanas y latinoamericanas en la España mediterránea: diferencias y similitudes», en Hernández Borge, J. y GonZÁlez Lopo, D. L., Mujer y emigración: una perspectiva plural, Universidad de Santiago de Compostela, pp. 151-171.

GozÁlvez Pérez, V. (2008c): «La inmigración extranjera en España: un capital humano para la demografía y para la economía», in ABATE, M. et al. (Dir.): Le Reti di Sviluppo: dalla Responsabilità Sociale delle imprese all'accountability della Pubblica Ammimistrazione. La gestione del cambiamento, IRSEM (Istituto di Ricerca dei Sistemi Evolutivi del Management), Bitonto (Bari), Italia, pp. 21-30.

Gozálvez Pérez, V. y López Trigal, L. (1999): «Jornaleros extranjeros en el campo español», Ería, n49, pp. 213-229.

INED (2005): «Tous les pays du monde (2005)», Population et Sociétés, no 414.

INED (2009): «Tous les pays du monde (2009)», Population et Sociétés, no 458.

IzQuierdo Escribano, A. (Dir.) (2006): Demografía de los extranjeros. Incidencia en el crecimiento de la población, Fundación BBVA, Madrid.

Martín Ruiz, J. F. (2007): «El nuevo orden neoeconómico mundial: la pobreza en Africa y sus factores», Anales de Geografía de la Universidad Complutense, vol. 27, no 2, pp. 77-103.

MÉNDEZ, R. (2008): «Inmigración y mercados de trabajos urbanos: tendencias recientes en la Región Metropolitana de Madrid», Scripta Nova. Revista electrónica de Geografía y Ciencias Sociales, vol. XII, nº 257. 
Ministerio de Trabajo e Inmigración. Observatorio Permanente de la Inmigración, Boletín Estadístico de Extranjería e Inmigración, núm. 16, abril de 2008; núm. 19, febrero 2009.

Ministerio de Trabajo, Boletín mensual de estadísticas laborales, abril 2010.

Pumares Fernández, P.; García Coll, A.; Asensio Hita, A: (2006): La movilidad laboral y geográfica de la población extranjera en España, Madrid, Ministerio de Trabajo y Asuntos Sociales, Observatorio Permanente de la Inmigración, $217 \mathrm{p}$.

Toulemon, L. (2004): «La fécondité des immigrées: nouvelles données, nouvelle approche», Population et Sociétés, no 400, INED, Paris.

Véron, J. (2006): L'urbanisation du monde, Paris, La Decouverte, 119 p.

Zapata Hernández, V. M. (2002): La inmigración extranjera en Tenerife, Cabildo Insular de Tenerife, $537 \mathrm{p}$. 